\title{
Effect of Support on Redox Stability of Iron Oxide for Chemical Looping Conversion of Methane
}

\author{
Nathan L Galinsky ${ }^{\mathrm{a}}$, Arya Shafiefarhood ${ }^{\mathrm{a}}$, Yanguang Chen ${ }^{\mathrm{a}, \mathrm{b}}$, Luke Neal ${ }^{\mathrm{a}}$ and Fanxing Li ${ }^{\mathrm{a} *}$ \\ a. Department of Chemical and Biomolecular Engineering, North Carolina State \\ University, 911 Partners Way, Raleigh, NC 27695-7905,USA.Email: Fli5@ncsu.edu \\ b. College of Chemistry \& Chemical Engineering, Northeast Petroleum University, Daqing, \\ Heilongjiang Province, 163318, P.R. China
}

\begin{abstract}
The chemical looping processes utilize lattice oxygen in oxygen carriers to convert carbonaceous fuels in a cyclic redox mode while capturing $\mathrm{CO}_{2}$. Typical oxygen carriers are composed of a primary oxide for active lattice oxygen storage and a ceramic support for enhanced redox stability and activity. Among the various primary oxides reported to date, iron oxide represents a promising option due to its low cost and natural abundance. The current work investigates the effect of support on the cyclic redox performance of iron oxides as well as the underlying mechanisms. Three ceramic supports with varying physical and chemical properties, i.e. perovskite-structured $\mathrm{Ca}_{0.8} \mathrm{Sr}_{0.2} \mathrm{Ti}_{0.8} \mathrm{Ni}_{0.2} \mathrm{O}_{3}$, fluorite-structured $\mathrm{CeO}_{2}$, and spinel-structured $\mathrm{MgAl}_{2} \mathrm{O}_{4}$, are investigated. The results indicate that the redox properties of the oxygen carrier, e.g. activity and long-term stability, are significantly affected by support and iron oxide interactions. The perovskite supported oxygen carrier exhibits high activity and stability compared to oxygen carriers with ceria support, which deactivate by as much as $75 \%$ within 10 redox cycles. The high stability of perovskite supported oxygen carrier is attributable to its high mixed ionic-electronic conductivity. Deactivation of ceria supported samples results from solidstate migration of iron cations and subsequent enrichment on the oxygen carrier surface. This leads to agglomeration and lowered lattice oxygen accessibility. Activity of $\mathrm{MgAl}_{2} \mathrm{O}_{4}$ supported oxygen carrier is found to increase during redox cycles in methane. The activity increase is a consequence of surface area increase caused by filamentous carbon formation and oxygen carrier fragmentation. While higher redox activity is desired for chemical looping processes, physical degradation of oxygen carriers can be detrimental.
\end{abstract}

Keywords: iron oxide, perovskite, chemical looping, $\mathrm{CO}_{2}$ capture, oxygen carrier

\section{Introduction}

$\mathrm{CO}_{2}$ emissions from the oxidation of fossil fuels can lead to unintended consequences of climate change.[1,2] Thus, novel approaches for $\mathrm{CO}_{2}$ capture, utilization, and sequestration (CCUS) are highly desired. The chemical looping strategy offers a potentially viable option for efficient carbonaceous fuel conversion with reduced carbon footprints. In the chemical looping process, an oxygen carrier is reduced and oxidized in a cyclic manner to convert carbonaceous fuels into 
separate streams of concentrated carbon dioxide and carbon-free products such as heat/electricity or hydrogen.[3-9] During the reduction step, the oxygen carrier, a.k.a. redox material, donates its lattice oxygen to the fuel while getting reduced, thereby converting the carbonaceous fuels to a gaseous mixture of carbon dioxide and water vapor. In the subsequent oxidation step(s), the oxygen deprived oxygen carrier is regenerated with gaseous oxygen and/or steam, resulting in heat and/or hydrogen products.[4,10] Since the effectiveness of chemical looping processes is largely affected by the performance of the oxygen carrier, i.e. its physical robustness, redox activity, stability, cost, etc., oxygen carrier development and optimization is a key area for chemical looping research.

A key component of an oxygen carrier is its active material or primary oxide, which directly participates in the abovementioned cyclic redox operations. Resulting from their suitable thermodynamic properties, oxides of first row transition metals such as iron, nickel, copper, manganese, and/or cobalt are among the most frequently used primary oxides for chemical looping applications.[3,11-16] With most unsupported metal oxides showing diminishing redox activities over multiple redox cycles[3,17], a support, which is typically selected from ceramic materials with relatively stable structures, is usually added to the primary oxide to improve its long-term redox performance. Among the various primary oxides, iron oxide(s) is particularly attractive due to its low cost, high oxygen capacity, and abundance.[3,18] In addition, reduced iron and wustite can be effective for hydrogen production through water-splitting.[5,12,19] A key challenge for iron oxide based oxygen carrier development is to obtain oxygen carriers with improved activity and recyclability. To address such a challenge, addition of supports including $\mathrm{Al}_{2} \mathrm{O}_{3}, \mathrm{MgAl}_{2} \mathrm{O}_{4}, \mathrm{CeO}_{2}, \mathrm{TiO}_{2}$, and $\mathrm{YSZ}$ have been investigated.[11,15,20-25] While supports can improve the activity and stability of iron based oxygen carriers [3,11,20,24,26,27], relatively few studies have investigated the roles of support for overall oxygen carrier performance.

Activity changes, i.e. deactivation or activation, for supported iron oxide over multiple redox cycles have been reported. [28-31] Bleeker et. al reported deactivation of iron oxide in a steamiron process.[29] The authors attributed deactivation to the decrease in surface area by iron (oxide) sintering. In contrast, iron oxide ores such as ilmenite are shown to activate during the chemical looping combustion (CLC) processes, possibly due to an increase in porosity over cyclic redox reactions.[28,30] $\mathrm{Li}$ et al. investigated $\mathrm{TiO}_{2}$ supported iron oxides.[32,33] Slight increase in activity of the oxygen carrier was observed with decreasing surface area and porosity through redox cycles. Based on inert marker experiments and density function theory (DFT) calculations, the authors proposed that high conductivities of electrons and lattice oxygen $\left(\mathrm{O}^{2-}\right)$ of the supported sample are responsible for improved redox activity of the supported iron oxide. A recent study by Galinsky et. al. have indicated that a mixed ionic-electronic conductive (MIEC) lanthanum strontium ferrite (LSF) support significantly improves the redox activity and stability of iron oxide based oxygen carriers.[34] The activity increase is believed to result from the excellent mixed conductivity of the LSF perovskite support. Shafiefarhood et. al. examined a novel strategy of covering iron oxide with an LSF shell for methane partial oxidation. [35] The 
LSF shell helped to achieve high activity, stability, and syngas selectivity over duration of 100 redox cycles. Similar to LSF, ceria is a frequently studied mixed-conductive support.[36-47] Ceria supported iron oxide is reported to possess good redox stability for cyclic reactions with $\mathrm{CH}_{4}$ (reduction) and steam (regeneration).[23] Bhavsar and Veser deposited $\mathrm{Fe}_{2} \mathrm{O}_{3}$ onto synthesized ceria via an incipient wetness method.[40] The authors report stable activity of the Fe-Ce-O oxygen carrier in hydrogen at $800^{\circ} \mathrm{C}$ with $\mathrm{H}_{2}$ and $\mathrm{CH}_{4}$ for 10 cycles. He et al. showed, at $850^{\circ} \mathrm{C}$ in $\mathrm{CH}_{4}$, that $\mathrm{Ce}-\mathrm{Fe}-\mathrm{O}$ with a $\mathrm{Ce} / \mathrm{Fe}$ of $7 / 3$ had stable activity between $\mathrm{Fe}_{2} \mathrm{O}_{3}$ and $\mathrm{FeO}$ phases over 20 redox cycles.[42] Contrast to the mixed-conductive perovskite and ceria, $\mathrm{MgAl}_{2} \mathrm{O}_{4}$ is a commonly encountered inert support.[22, 24, 31, 48-52] Johansson et al. concluded that sintering temperature has a significant effect to the activity of $\mathrm{Fe}_{2} \mathrm{O}_{3}$ supported with $\mathrm{MgAl}_{2} \mathrm{O}_{4}$.[22] They observed a slight increase in redox activity over 9-17 cycles in a 1:1 ratio of $\mathrm{CH}_{4}$ and $\mathrm{H}_{2} \mathrm{O}$. The authors postulated that the activation is resulted from cracks and pore size change. To summarize, although a large number of supported iron oxides are tested, their deactivation/activation mechanisms have not been thoroughly investigated.

This article aims to investigate the roles of support on the redox activity and long-term stability of iron oxide based oxygen carriers. Three ceramic supports, i.e. perovskite-structured $\mathrm{Ca}_{0.8} \mathrm{Sr}_{0.2} \mathrm{Ti}_{0.8} \mathrm{Ni}_{0.2} \mathrm{O}_{3}$, fluorite-structured $\mathrm{CeO}_{2}$, and spinel-structured $\mathrm{MgAl}_{2} \mathrm{O}_{4}$ are investigated.

Of these supports, $\mathrm{Ca}_{0.8} \mathrm{Sr}_{0.2} \mathrm{Ti}_{0.8} \mathrm{Ni}_{0.2} \mathrm{O}_{3}$ and $\mathrm{CeO}_{2}$ represent mixed-conductors with distinct crystal structures. $\mathrm{MgAl}_{2} \mathrm{O}_{4}$, on the other hand, is a frequently encountered inert support. Through detailed investigation of the relationship between oxygen carrier activation/deactivation and its support conductivity, surface and phase compositions, morphology, and surface area, general design principles for highly active and recyclable oxygen carriers are obtained.

\section{Experimental Methods}

\subsection{Oxygen Carrier Synthesis:}

Several oxygen carriers are synthesized using three approaches, i.e. solid state reaction (SSR), co-precipitation $(\mathrm{CP})$, and citric acid (CA) methods. The oxygen carriers tested are shown in Table 1. Oxygen carrier samples prepared via SSR reactions are sintered at $1,000-1,050^{\circ} \mathrm{C}$ while those prepared through $\mathrm{CP}$ and $\mathrm{CA}$ methods are sintered at $800-1,000^{\circ} \mathrm{C}$. X-ray powder diffraction (XRD) is used to confirm the formation of the desired phases. A brief summary of these synthesis methods is given in the following section. Further details can be found in several references. [34,53,54] To ensure generality of the mechanistic findings, synthesis method and compositions of ceria and $\mathrm{MgAl}_{2} \mathrm{O}_{4}$ supported oxygen carriers are consistent with those reported in literature [22,24-26,35,36,39-47]. Activity and recyclability of the ceria based oxygen carriers in the current study are comparable, if not higher, than those reported in previous literatures under similar operating conditions (see Supplemental Figure S3).

Table 1. List of oxygen carriers synthesized. 


\begin{tabular}{|c|c|}
\hline Material & Method and composition \\
\hline 1) $\mathrm{Fe}_{2} \mathrm{O}_{3}: \mathrm{CeO}_{2}$ & SSR (3:7 molar ratio) \\
\hline 2) $\mathrm{Fe}_{2} \mathrm{O}_{3}: \mathrm{CeO}_{2}$ & Co-precipitation (3:7 molar ratio) \\
\hline 3) $\mathrm{Fe}_{2} \mathrm{O}_{3}: \mathrm{CeO}_{2}$ & Co-precipitation (4:6 molar ratio) \\
\hline 4) $\mathrm{Fe}_{2} \mathrm{O}_{3}: \mathrm{Ca}_{0.8} \mathrm{Sr}_{0.2} \mathrm{Ti}_{0.8} \mathrm{Ni}_{0.2} \mathrm{O}_{3}$ & citric acid (3:7 molar ratio) \\
\hline 5) $\mathrm{Fe}_{2} \mathrm{O}_{3}: \mathrm{MgAl}_{2} \mathrm{O}_{4}$ & SSR (3:7 weight ratio) \\
\hline
\end{tabular}

SSR samples are prepared by measuring calculated amounts of precursors $\mathrm{Fe}_{2} \mathrm{O}_{3}(99.9 \%$, Noah Chemicals), $\mathrm{CeO}_{2}$ (99.9\%, Noah Chemicals), and $\mathrm{MgAl}_{2} \mathrm{O}_{4}$ (99.9\%, Noah Chemicals) and placing them for 6 hours in a planetary ball mill (XBM4X, Columbia International) at a rotation of $250 \mathrm{rpm}$. Following the milling step, the resulting mixture is pressed into pellets by a hydraulic press (YLJ-15T, MTI Corporation) at a pressure of 20MPa. The pellets are then annealed, fractured, and sieved to powder ( $<150$ microns) for testing.

The co-precipitation method involves taking calculated precursor nitrates $\mathrm{Fe}\left(\mathrm{NO}_{3}\right)_{3} \cdot 9 \mathrm{H}_{2} \mathrm{O}$ (98+\%, Sigma-Aldrich) and $\mathrm{Ce}\left(\mathrm{NO}_{3}\right)_{3} \cdot 6 \mathrm{H}_{2} \mathrm{O}(99 \%$, Sigma-Aldrich) into solution with deionized water. The solution is then mixed at $70^{\circ} \mathrm{C}$ where a $10 \%$ ammonia solution is introduced drop wise to increase the $\mathrm{pH}$ of the solution to 9 . The solution is allowed to precipitate at $70^{\circ} \mathrm{C}$ for 1 hour. It is then aged for 2 hours. The resulting solids are subsequently filtered and washed thoroughly with deionized water and ethanol. They are then dried at $110^{\circ} \mathrm{C}$ for 24 hours. Calcination is performed at $300^{\circ} \mathrm{C}$ to convert the hydroxide groups into oxides, and then the particles are crushed into powder and sintered for 6 hours at $800^{\circ} \mathrm{C}$. A sintering temperature of $800{ }^{\circ} \mathrm{C}$ is used for $\mathrm{CP}$ sample to reproduce oxygen carriers reported in literature. [53]

The citric acid method is used to prepare the $\mathrm{Fe}_{2} \mathrm{O}_{3}: \mathrm{Ca}_{0.8} \mathrm{Sr}_{0.2} \mathrm{Ti}_{0.8} \mathrm{Ni}_{0.2} \mathrm{O}_{3}$ oxygen carrier from $\mathrm{Fe}_{2} \mathrm{O}_{3}$ nanoparticles $\left(<50 \mathrm{~nm}\right.$, Sigma-Aldrich), nitrate salts, and alkoxides. First, $\mathrm{Fe}_{2} \mathrm{O}_{3}$ nanoparticles are dispersed in ethanol via sonication. The solution is settled for 6 hours to deposit the nanoparticles and to remove the upper liquid of the solution. The nanoparticles are redispersed in deionized water and sonicated. A second solution comprised of the precursors $\mathrm{Ca}\left(\mathrm{NO}_{3}\right)_{2} \cdot 4 \mathrm{H}_{2} \mathrm{O}\left(\geq 99.9 \%\right.$, Sigma-Aldrich), $\mathrm{Sr}\left(\mathrm{NO}_{3}\right)_{2}$ (ACS Reagent, Noah Chemicals), and $\mathrm{Ni}\left(\mathrm{NO}_{3}\right)_{2} \cdot 6 \mathrm{H}_{2} \mathrm{O}$ (Sigma-Aldrich) are placed into deionized water. Citric acid and EDTA are used as chelating agents. An ammonia solution is used to change the $\mathrm{pH}$ of the solution to 8. A third solution containing ethanol and citric acid is used to dissolve $\mathrm{Ti}\left(\mathrm{OC}_{4} \mathrm{H}_{9}\right)_{4}(97 \%$, Sigma-Aldrich). Solutions containing the metal ions are mixed thoroughly. The dispersed nanoparticles are introduced to the solution and heated at $80^{\circ} \mathrm{C}$ under mixing conditions until gel formation. The gel is then dried at $120^{\circ} \mathrm{C}$ for 6 hours followed by calcination at $1,000^{\circ} \mathrm{C}$ for 6 hours. 


\subsection{Reactivity Studies}

Reactivity studies are conducted in a SETARAM SETSYS Evolution Thermal Gravimetric Analyzer (TGA). Up to $75 \mathrm{mg}$ powdery samples are loaded into the TGA. Both $\mathrm{H}_{2}$ and $\mathrm{CH}_{4}$ are used as the reducing gas and $\mathrm{O}_{2}$ is used as the oxidizing gas. Gas flow rates are adjusted so that there is $10 \%$ reducing $\left(\mathrm{H}_{2}\right.$ or $\left.\mathrm{CH}_{4}\right)$ or oxidizing $\left(\mathrm{O}_{2}\right)$ gas balanced with inert $(\mathrm{He})$. Unless otherwise specified, the temperature inside the TGA is held at $900^{\circ} \mathrm{C}$ with a total flow rate of $300 \mathrm{~mL} / \mathrm{min}$. Carbon formations are quantified on samples reduced in methane. Carbon content is estimated using the TGA curves by examining the weight gain after near complete reduction of the oxygen carrier samples. Such an analysis method, which was reported in prior literatures $[55,56]$, assumes that sample weight loss from further reduction is minimal compared to the weight gain from coke formation.

\subsection{Sample Characterizations}

A number of characterization tools are utilized to characterize surface areas, pore size distributions, bulk compositions, crystal structure, and morphology of the oxygen carriers before and after redox reactions. X-ray powder diffraction (XRD) is carried out to analyze crystal phase compositions and crystallite sizes before and after redox cycles. XRD patterns are recorded using a Rigaku SmartLab X-ray diffractometer with $\mathrm{Cu}-\mathrm{K} \alpha(\lambda=0.1542)$ radiation operating at $40 \mathrm{kV}$ and $44 \mathrm{~mA}$. Scans are performed stepwise with a $0.1^{\circ}$ step size holding for 3.5 seconds at each step between a $20-80^{\circ}$ angle range (20). Surface areas and pore size distributions are measured using a BET surface analyzer (Quantachrome QuadraSorb Station 1) using nitrogen physisorption at $77.3 \mathrm{~K}$. For image capturing, a scanning electron microscope (SEM, Hitachi S3200) is used to observe surface morphology and structure. The same instrument is used to perform X-ray spectroscopy (EDX) scans on the particles to obtain bulk and area compositions at a wide range of accelerating voltages (10-30 keV). Transmission Electron Microscopy (TEM, JEOL JEM 2010F) with $200 \mathrm{keV}$ accelerating voltage are used to characterize carbon formation on the $\mathrm{MgAl}_{2} \mathrm{O}_{4}$ sample. X-ray photoelectron spectroscopy (XPS) was used to probe the nearsurface composition of the fresh and cycled ceria supported oxygen carrier. The custom built system was comprised of a Thermo-Fisher Alpha 110 hemispherical energy analyzer, a ThermoFisher XR3, 300 watt duel anode $\mathrm{x}$-ray source, and a chamber with a base pressure $1 * 10^{-9}$ Torr. The Mg anode was used. Survey spectra were taken with a pass energy of $100 \mathrm{eV}$, and narrow scans were taken with a pass energy of $20 \mathrm{eV}$. The spectra were processed in CasaXPS.

\section{Results}

\subsection{Activity Comparisons}

Redox activities of oxygen carriers under $\mathrm{H}_{2}$ and $\mathrm{CH}_{4}$ environments are summarized in Figure 1. Second cycle activity data is used for comparison purpose since they tend to be more stable than first cycle results. Average conversion rates (conversion \%/min.) to achieve $11 \%$ conversion and 
$33 \%$ conversion, which correspond to $\mathrm{Fe}_{2} \mathrm{O}_{3}$ to $\mathrm{Fe}_{3} \mathrm{O}_{4}$ and $\mathrm{Fe}_{2} \mathrm{O}_{3}$ to $\mathrm{FeO}$ respectively, are used to characterize the activities of the oxygen carrier. The conversion profiles are provided in Figure $\mathrm{S} 1$ of the supplemental document. Oxygen carrier conversion is defined by Equation 1:

$x_{O C}=\frac{\left(m_{\text {int. }}-m_{i}\right) * 100 \%}{m_{\text {int }} * x_{O 2}}$

where $\mathrm{m}_{\mathrm{int}}$ is the initial weight of the oxygen carrier, $\mathrm{m}_{\mathrm{i}}$ is mass at time $i$ during the reduction, and $\mathrm{x}_{\mathrm{O} 2}$ is the amount of active lattice oxygen in the oxygen carrier. Average conversion rates are determined by taking the conversion of $11 \%$ or $33 \%$ and dividing it with the time to achieve the corresponding conversion.

As can be seen from Figure 1, the perovskite supported oxygen carrier has a higher activity than those of $\mathrm{CeO}_{2}$ and $\mathrm{MgAl}_{2} \mathrm{O}_{4}$ supported oxygen carriers in both hydrogen and methane. Compared to the activity to achieve $11 \%$ conversion, oxygen carriers exhibit higher activity to achieve $33 \%$ when $\mathrm{H}_{2}$ is the reducing gas. This indicates that, between 0 and $33 \%$ conversion of the oxygen carrier, reaction rates tend to increase with deeper reduction of the iron oxide. Such a sigmoidal behavior has been reported in previous literatures for ilmenite reduction.[57] An activation period, which is associated with ion migration, is proposed to be responsible for the relatively low activity at the initial stage of the reduction. When $\mathrm{CH}_{4}$ is used as the reducing gas; however, oxygen carrier activity tends to decrease with increasing degree of reductions. The difference in reduction behavior of iron oxide in $\mathrm{H}_{2}$ and $\mathrm{CH}_{4}$ can be partially attributed to the difference in diffusivities of $\mathrm{H}_{2}$ and $\mathrm{CH}_{4}$ molecules as well as the surface activation scheme. All the oxygen carriers investigated exhibit lower activities in $\mathrm{CH}_{4}$ than those in $\mathrm{H}_{2}$. This can be explained by the high stability $\mathrm{C}-\mathrm{H}$ bond in methane.

Figure 2 compares the activity change for the oxygen carriers between the $2^{\text {nd }}$ and $10^{\text {th }}$ reduction cycles. As can be seen, the perovskite supported iron oxide deactivates by approximately $16 \%$ from cycle 2 to 10 . While all the ceria samples exhibit deactivation, 4:6 (Fe: $\mathrm{Ce}$ ) co-precipitated ceria supported oxygen carrier deactivates to the largest extent ( 75\%). In contrast, $\mathrm{MgAl}_{2} \mathrm{O}_{4}$ supported oxygen carrier showed activity increase by almost $60 \%$ over the 9 redox cycles. The potential causes of activity changes are discussed in the following sections. It is noted that the current study focuses on reduction cycles since oxidation rates tend to be similar to, if not faster than, the reduction steps when $\mathrm{CH}_{4}$ is used as the fuel (See Figure S2 in Supplemental document). 

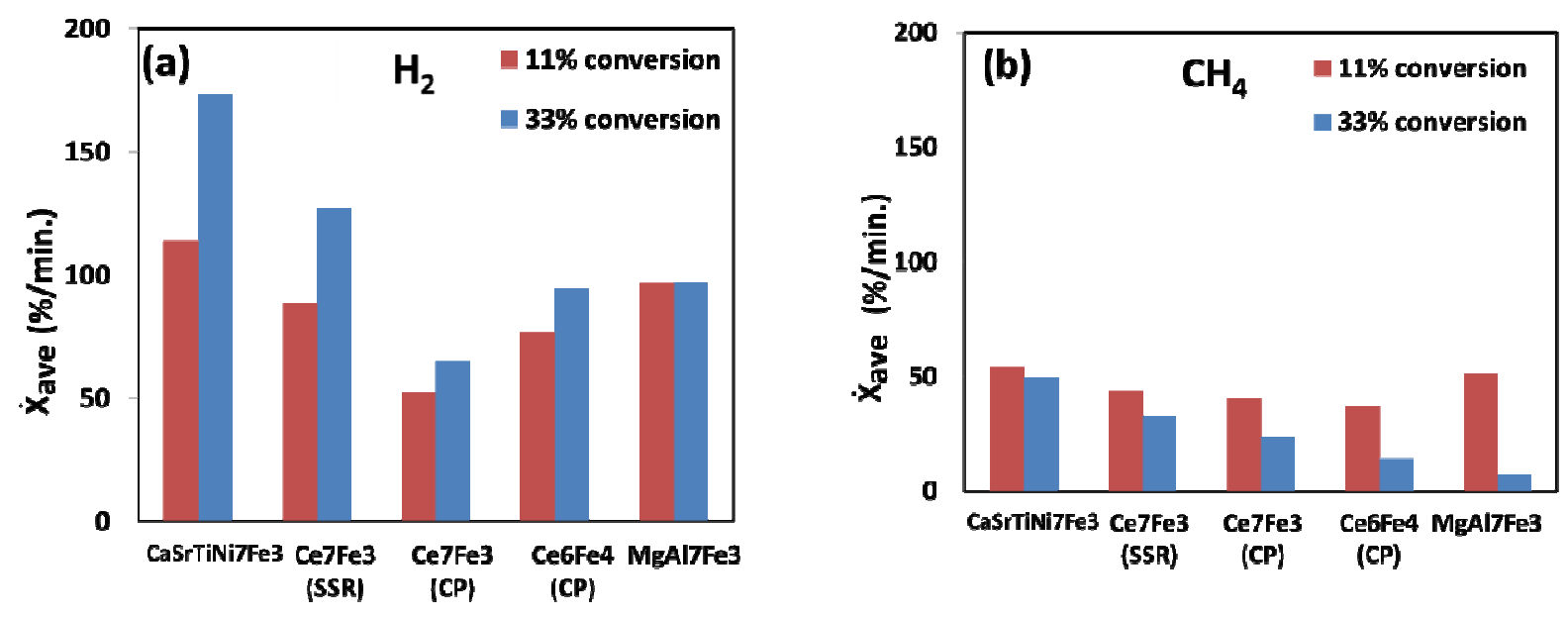

Figure 1- Comparison of the $2^{\text {nd }}$ cycle reduction of the various oxygen carriers by comparison of average conversion rate $\left(\dot{X}_{\text {ave }}\right)$ to achieve $11 \%$ and $33 \%$ conversion in (a) $10 \% \mathrm{H}_{2}$ and (b) $10 \% \mathrm{CH}_{4}$ at $900^{\circ} \mathrm{C}$.

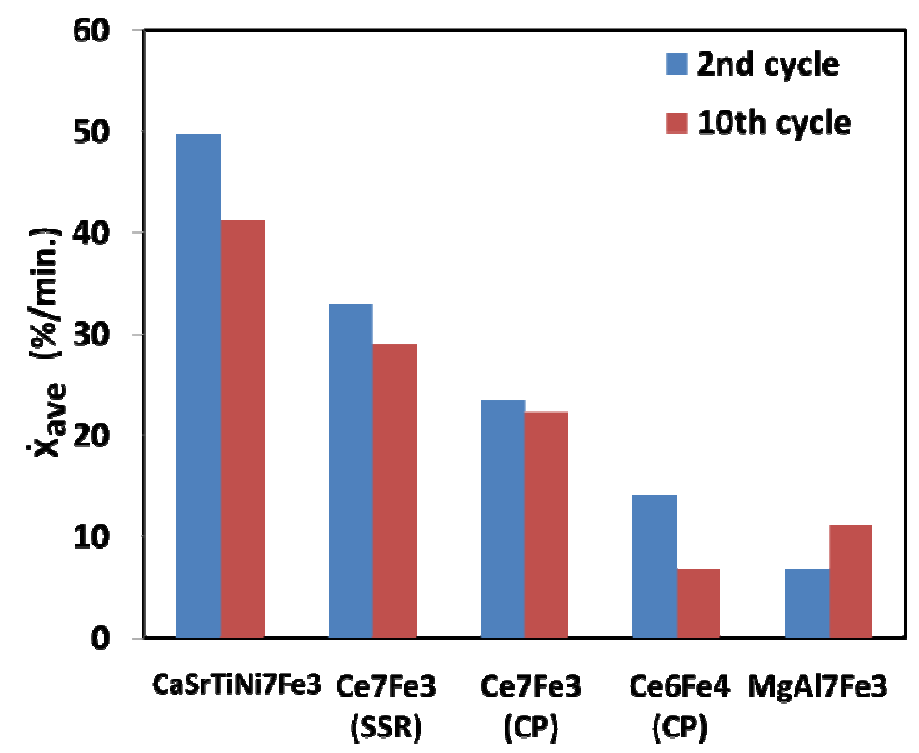

Figure 2- Average conversion rate $\left(\dot{X}_{\text {ave }}\right)$ to $33 \%$ conversion comparison between $2^{\text {nd }}$ and $10^{\text {th }}$ cycles of the various oxygen carriers at $900^{\circ} \mathrm{C}$ in $10 \% \mathrm{CH}_{4}$.

\section{2 $\mathrm{Ca}_{0.8} \mathrm{Sr}_{0.2} \mathrm{Ti}_{0.8} \mathrm{Ni}_{0.2} \mathrm{O}_{3}$ supported $\mathrm{Fe}_{2} \mathrm{O}_{3}$}

The multi-cyclic redox activities of perovskite supported iron oxide with $\mathrm{H}_{2}$ and $\mathrm{CH}_{4}$ are shown in Figure 3. Excellent stability of the oxygen carrier in $\mathrm{H}_{2}$ is observed within the second to tenth redox cycles. The activation of the perovskite from the first to second cycles in $\mathrm{H}_{2}$ may be due to incomplete perovskite phase formation of the oxygen carrier. In contrast, the same oxygen carrier deactivates by $15 \%$ within the first 5 redox cycles when methane is used as the fuel. 
When cycled further, the perovskite supported oxygen carrier is more stable, showing only slight deactivation $(<1 \%)$ between cycle 5 and 50 . Deactivation in the short term is likely to be caused by phase instability of the support. While the surface area also decreases, our previous works show very weak correlation between activity and surface area with regards to perovskite supported iron oxide.[34,35]

XRD spectra of the fresh and ten cycle (ending on oxidation) perovskite supported oxygen carrier are shown in Figure 4. As indicated by the absence of $\mathrm{Ni}$ oxides, $\mathrm{Ni}$ is incorporated in the perovskite B-site in the fresh sample. A slight addition of $\mathrm{Ni}$ to the $\mathrm{B}$-site did not change the diffraction pattern of the parent perovskite (Orthorhombic $\mathrm{Ca}_{0.8} \mathrm{Sr}_{0.2} \mathrm{TiO}_{3}$ ) to any significant extent. After 10 cycles, a distinct Ni-Fe spinel structure is observed. This indicates that $\mathrm{Ni}$ is likely to be partially substituted by $\mathrm{Fe}$ since substitution of $\mathrm{Ni}^{2+}$ with $\mathrm{Fe}^{3+}$ is likely to result in a more stable $\mathrm{Ca}_{\mathrm{x}} \mathrm{Sr}_{1-\mathrm{x}} \mathrm{Ti}_{\mathrm{y}} \mathrm{M}_{1-\mathrm{y}} \mathrm{O}_{3-\delta}$ structure from a charge balance standpoint. This is consistent with refinement results which indicate a lower lattice constant in the $\mathrm{b}$ direction, causing unit cell volume to decrease by nearly $0.6 \%$ (See SI Table S1). Such a decrease can be explained by the addition of a secondary $\mathrm{B}$-site dopant, as $\mathrm{Fe}^{3+}$ is notably smaller than $\mathrm{Ni}^{2+}$. The activity of the oxygen carrier becomes stable once the phase transformation is completed.

From TGA curves shown in Figure 5, notable coke formation starts to occur when the oxygen carrier is close to being fully reduced. This is expected due to the high activity of reduced $\mathrm{Ni}$ (and $\mathrm{Fe}$ ) for methane dissociation.[58-60] Coke formation is calculated from the TGA curves as shown in Figure 5. From the TGA, it can be observed that carbon formation does not begin until near complete reduction of the iron oxide to metallic iron ( 9\% weight loss). This agrees with our previous work on perovskite supported iron oxides.[34] It is noted that oxygen carrier conversion is typically limited to less than $50 \%$ for iron oxide based oxygen carriers. Therefore, carbon formation in actual process operations can be low. BET surface area results (see Table 2) indicate decreasing surface area with increase redox cycles. The surface area is decreased by almost a factor of 4 over the first 10 cycles. The corresponding deactivation; however, is less than $15 \%$. No volume expansion is observed for this oxygen carrier over 50 redox cycles. To summarize, perovskite supported iron oxide, although deactivates slightly in the first few redox cycles, exhibits high redox activity and stability over multiple redox cycles. The high electronic and ionic conductivities are likely to be responsible for the high activity of the oxygen carrier. 

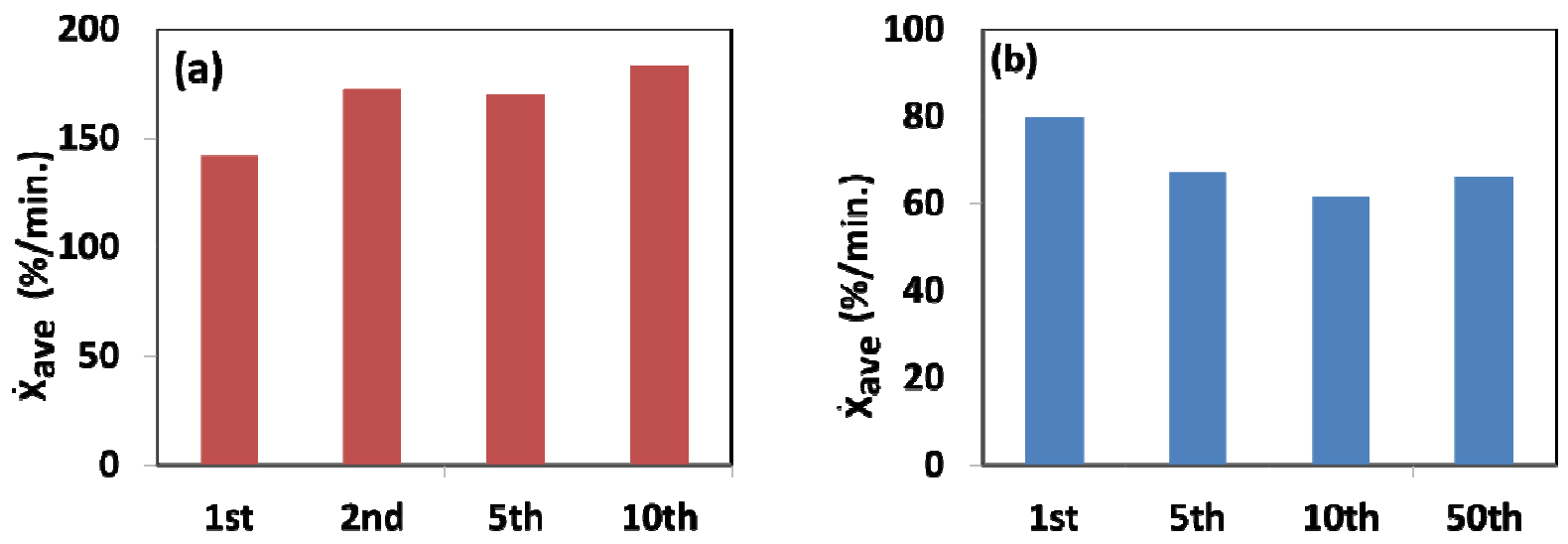

Figure 3- Average conversion rate $\left(\dot{X}_{\text {ave }}\right.$ ) to achieve $33 \%$ conversion of $\mathrm{Ca}_{0.8} \mathrm{Sr}_{0.2} \mathrm{Ti}_{0.8} \mathrm{Ni}_{0.2} \mathrm{O}_{3}$ supported $\mathrm{Fe}_{2} \mathrm{O}_{3}$ via CA method with (a) 10 cycles with $\mathrm{H}_{2}$ and (b) 50 -cycles with $\mathrm{CH}_{4}$ at $900^{\circ} \mathrm{C}$.
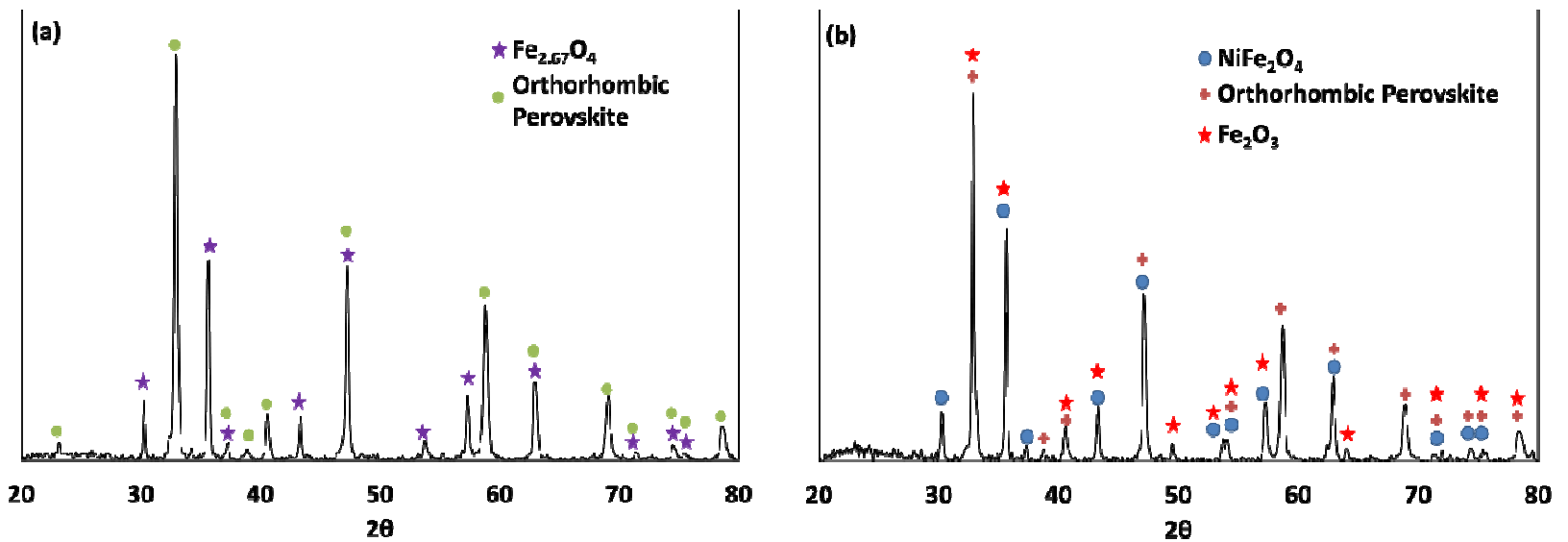

Figure 4- XRD analyses of the (a) fresh and (b) 10-cycled CSTN supported iron oxide samples. 


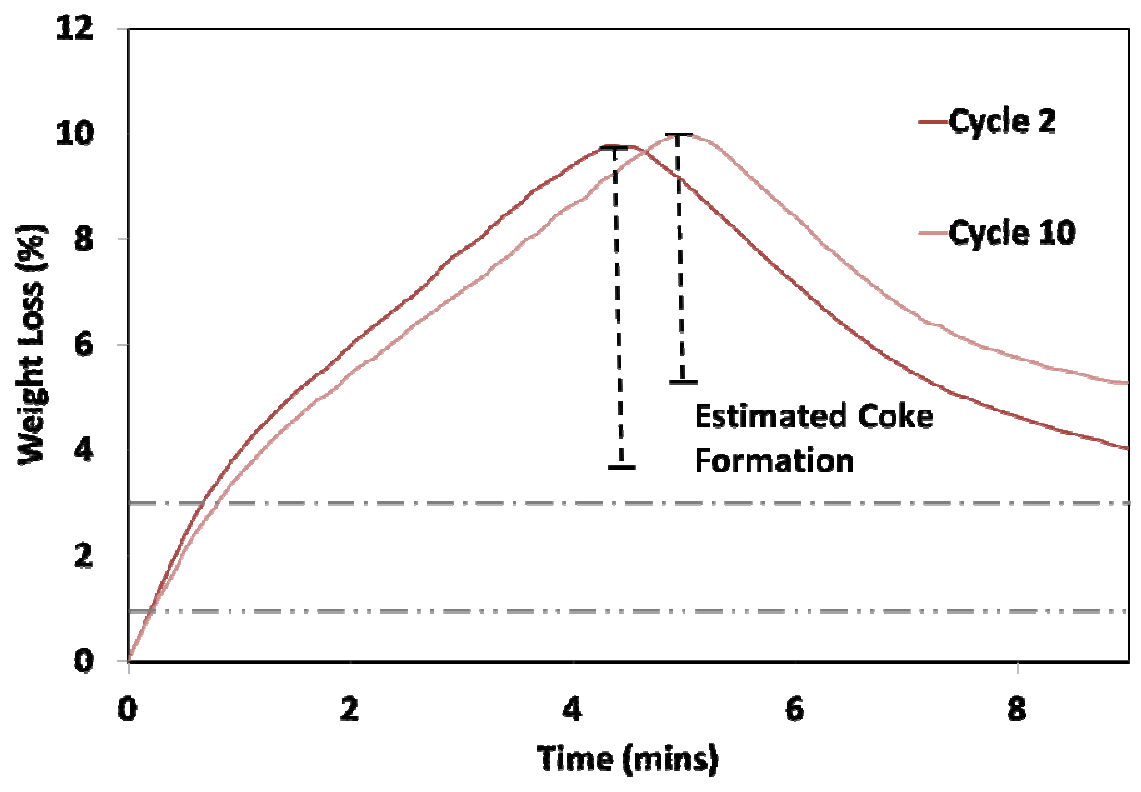

Figure 5- Oxygen carrier weight loss (TGA) curves for cycle 2 and cycle 10 of the $\mathrm{Fe}_{2} \mathrm{O}_{3}: \mathrm{CSTN}$ (CA) in $\mathrm{CH}_{4}$ at $900^{\circ} \mathrm{C}$. Vertical lines represent the estimated coke formation for the reaction with methane. Lower horizontal line represents the demarcation between $\mathrm{Fe}_{2} \mathrm{O}_{3} / \mathrm{Fe}_{3} \mathrm{O}_{4}$ and $\mathrm{Fe}_{3} \mathrm{O}_{4} / \mathrm{FeO}$; Upper horizontal line represents the demarcation between $\mathrm{Fe}_{3} \mathrm{O}_{4} / \mathrm{FeO}$ and $\mathrm{FeO} / \mathrm{Fe}$ (calculated based on average oxidation state).

Table 2. Carbon Formation (within 10 mins. of reduction in $\mathrm{CH}_{4}$ ) and BET surface areas of the CSTN supported iron oxide oxygen carrier

\begin{tabular}{|l|c|c|}
\hline & $2^{\text {nd }}$ reduced & $10^{\text {th }}$ cycle reduced \\
\hline $\begin{array}{l}\text { Carbon Formation }(\%)(10 \\
\text { minute reduction) }\end{array}$ & 5.7 & 4.7 \\
\hline $\begin{array}{l}\text { BET surface areas (oxidized } \\
\text { samples) }\left(\mathrm{m}^{2} / \mathrm{gm}\right)\end{array}$ & 4.39 & 1.24 \\
\hline
\end{tabular}

\section{3 $\mathrm{CeO}_{2}$ supported $\mathrm{Fe}_{2} \mathrm{O}_{3}$}

As shown in Figures 2 and $6, \mathrm{CeO}_{2}$ supported iron oxides exhibit high initial activity with $\mathrm{CH}_{4}$. However, their activities decrease over multiple redox cycles. Change in activity for a coprecipitated $\mathrm{Fe}_{2} \mathrm{O}_{3}: \mathrm{CeO}_{2}$ (4:6) sample is further illustrated in Figure 6. As can be seen, activity of the oxygen carrier decreases from cycle 1 onwards. By cycle 10, the sample reduction rate has decreased by $75 \%$. When the oxygen carrier is cycled further, it is unable to achieve $33 \%$ conversion during the 10 -minute reduction period. The decreasing reduction rate also affects the 
onset of coke formation. While carbon formation is observed during the first 5 redox cycles, coke formation is insignificant in the subsequent cycles. This can be explained by incomplete reduction of the oxygen carrier: The cycled oxygen carriers, being less active, are not fully reduced during the 10-minutes reduction period and contain active lattice oxygen. The lack of metallic iron on oxygen carrier surface and the high lattice oxygen conductivity of the $\mathrm{CeO}_{2}$ support lead to reduced coke formation by (i) decreasing methane dissociation rate; (ii) oxidation of surface-carbon with active lattice oxygen.

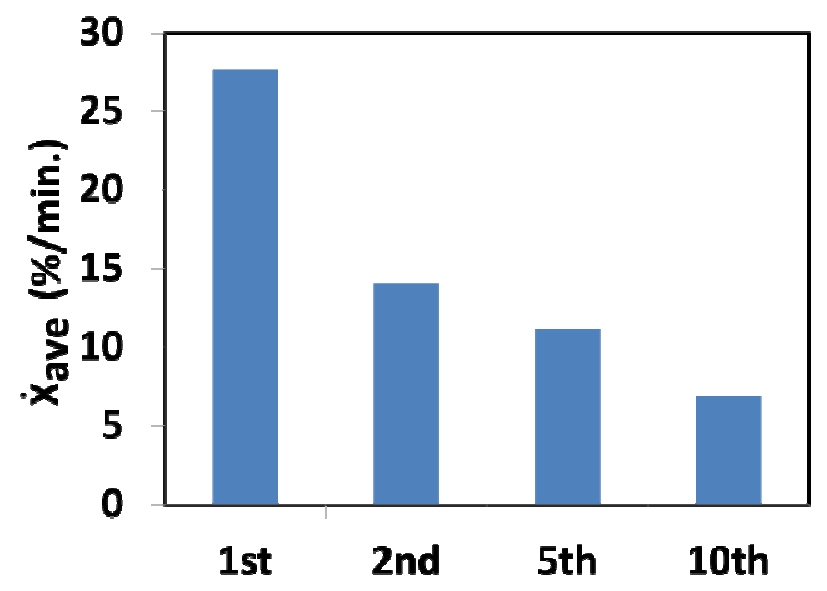

Figure 6- Average reduction rate $\left(\dot{X}_{\text {ave }}\right)$ to achieve $33 \%$ conversion of $\mathrm{Fe}_{2} \mathrm{O}_{3}: \mathrm{CeO}_{2}$ (4:6) prepared via a co-precipitation route over the first 10 redox cycles during a 50 cycle experiment. Reducing gas: methane; Oxidizing gas: oxygen; Temperature: $900^{\circ} \mathrm{C}$.

XRD spectra of the fresh, $1^{\text {st }}$ cycle reduced, $50^{\text {th }}$ cycle oxidized, and $51^{\text {st }}$ cycle reduced samples are summarized in Figure 7. As can be seen, oxidized oxygen carriers (fresh and $50^{\text {th }}$ cycled) indicate only the primary metal oxide $\left(\mathrm{Fe}_{2} \mathrm{O}_{3}\right)$ and support $\left(\mathrm{CeO}_{2}\right)$ phases. $\mathrm{Fe}_{2} \mathrm{O}_{3}$ peaks are less intense after 50 cycles, which corresponds to smaller crystallite sizes (see Table 3 ). With respect to the reduced oxygen carriers, $1^{\text {st }}$ cycle reduced oxygen carrier is composed of iron and $\mathrm{CeO}_{2}$ phases. The results are consistent with TGA weight loss as well as observations reported by Galvita et. al.[36] The $51^{\text {st }}$ reduced oxygen carrier; however, consists of a ternary phase of metallic iron, $\mathrm{CeO}_{2}$, and $\mathrm{CeFeO}_{3}$ perovskite. The formation of $\mathrm{CeFeO}_{3}$ has also been reported in previous literatures. [23] As can be seen in Table 3, surface area of the sample is reduced by nearly an order of magnitude during 50 cycles. PSDs indicate a smaller amount of meso-pores in the cycled sample, likely due to sintering (see Figure S5 in Supplemental Document). 

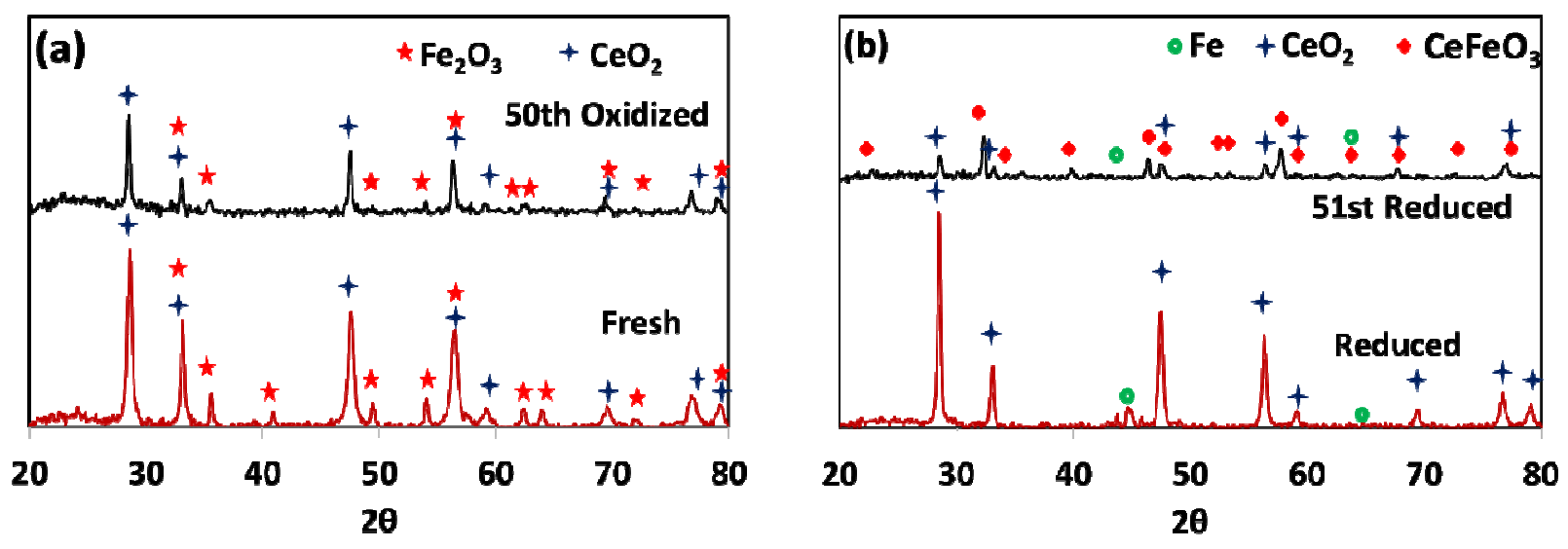

Figure 7- XRD of the (a) fresh and 50th cycle oxidized (b) $1^{\text {st }}$ reduced and $51^{\text {st }}$ reduced during the redox in methane and oxygen of the (4:6) co-precipitation $\mathrm{Fe}_{2} \mathrm{O}_{3}: \mathrm{CeO}_{2}$ sample.

Table 3. Summary of BET, crystallite sizes, and carbon formation study on the $\mathrm{Fe}_{2} \mathrm{O}_{3}: \mathrm{CeO}_{2}(4: 6)$ $\mathrm{CP}$ oxygen carrier

\begin{tabular}{|l|c|c|}
\hline & Fresh $\left(2^{\text {nd }}\right.$ reduced $)$ & $50^{\text {th }}$ cycle \\
\hline $\begin{array}{l}\text { Carbon Formation }(\%)(10 \\
\text { minute reduction) }\end{array}$ & 2.0 & 0 \\
\hline $\begin{array}{l}\text { BET Surface Area (oxidized } \\
\text { samples) }\left(\mathrm{m}^{2} / \mathrm{gm}\right)\end{array}$ & 14.6 & 1.6 \\
\hline Crystallite Size $\mathrm{CeO}_{2}(\AA)$ & 410 & 570 \\
\hline Crystallite ${\mathrm{Size} \mathrm{Fe}_{2} \mathrm{O}_{3}(\AA)}$ & 680 & 140 \\
\hline
\end{tabular}

To further investigate the sintering behavior, morphology and compositions of the oxygen carriers are examined using SEM and EDX (see supplemental document figure S6 and tables S2 and S3). As the material is cycled, sintering of these particles take place, leading to larger particles with reduced porosity. This is consistent with the changes in surface area and PSD. EDX analyses are performed to obtain the average (near surface) composition of the oxygen carrier. Fe:Ce ratio for as-prepared sample increases from 2.1 to 6.5 when acceleration voltage decreases from $30 \mathrm{keV}$ to $10 \mathrm{keV}$ (Figure S6). Since EDX detects elemental compositions within a few micrometers from the sample surface, iron oxide is likely to have been enriched on the oxygen carrier surface. To determine the surface composition changes over redox cycles, EDX area scans on the fresh, $51^{\text {st }}$ oxidation, and $52^{\text {nd }}$ reduced samples are conducted (See 
Supplemental Table S2). Redox reactions appear to enhance the surface enrichment of iron oxides. For instance, the Fe:Ce ratio of $51^{\text {st }}$ oxidized sample is 2.4 times higher than that of the as-prepared sample. Large agglomerates of iron oxide are also observed. The reduced oxygen carriers tend to be more homogeneous although isolated regions enriched with iron are nevertheless identified. Increased homogeneity of the reduced sample can be explained by $\mathrm{CeFeO}_{3}$ phase formation through solid state reactions between $\mathrm{Fe}$ and $\mathrm{Ce}$ oxides, as confirmed by XRD.

X-ray photoelectron spectroscopy (XPS) is performed on fresh and $51^{\text {st }}$ oxidized oxygen carrier as shown in Figure 8. XPS results indicate that nearly 40 at.\% of the initial oxygen carrier surface is iron. Upon examining the $51^{\text {st }}$ oxidized oxygen carrier, enrichment of iron to almost 80 at.\% was observed. Since XPS is sensitive to atoms within a few $\mathrm{nm}$ below the sample surface, these results, along with the EDX data, further confirm iron cation diffusion and enrichment on the sample surface.
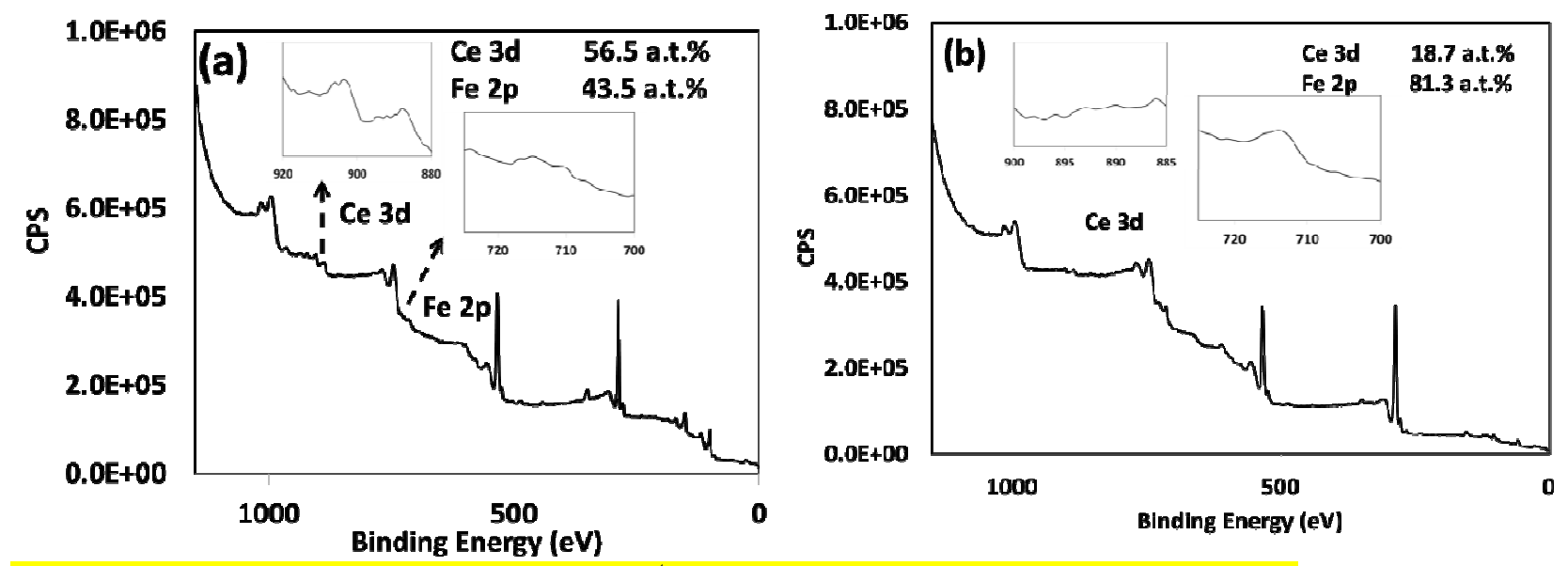

Figure 8- XPS of the (a) fresh and (b) $51^{\text {st }}$ oxidized ceria supported oxygen carrier

While surface iron enrichment on $\mathrm{CeO}_{2}$ supported iron oxide has not been reported, outward growth of iron in unsupported iron oxides during redox cycles has been reported in literature.[29,33] This can be explained by lower ionic diffusivity of $\mathrm{O}^{2-}$ compared to $\mathrm{Fe}^{\mathrm{x}+}(\mathrm{x}=2$ or 3) in both magnetite and wustite. As a result, cations of iron need to migrate out from the oxide lattice to react with oxygen during the oxidation step. Since the iron cations may not migrate back during the reduction cycles, continued redox cycles leads to continued surface enrichment of iron oxide layers. A similar phenomenon of iron migration is also reported by Zhao et al.[57] for the reduction of ilmenite $\left(\mathrm{FeTiO}_{3}\right)$ to $\mathrm{Fe}$ and $\mathrm{TiO}_{2}$ in $\mathrm{H}_{2}$. Although $\mathrm{CeO}_{2}$ possesses good mixed-conductivity for electron and lattice oxygen transfer, migration of $\mathrm{Fe}$ and $\mathrm{Ce}$ cations are likely to occur throughout the redox cycles, as evidenced by mixed $\mathrm{Fe}-\mathrm{Ce}$ oxide formation. To compare, the energy barrier for $\mathrm{Fe}^{3+}$ diffusion in $\mathrm{Ca}_{0.8} \mathrm{Sr}_{0.2} \mathrm{Ti}_{0.8} \mathrm{Ni}_{0.2} \mathrm{O}_{3}$ perovskite is 
likely to be high: typical energy barrier for the diffusion of B-site cation in acceptor-doped perovskites is $\sim 3 \mathrm{eV}$ compared to $<1 \mathrm{eV}$ for $\mathrm{O}^{2-}$ diffusion.[63,64] Therefore, $\mathrm{Ca}_{0.8} \mathrm{Sr}_{0.2} \mathrm{Ti}_{0.8} \mathrm{Ni}_{0.2} \mathrm{O}_{3}$ supported iron oxide possesses a more stable structure by allowing facile lattice oxygen exchange. In contrast, Fe cations may be easier to migrate than oxygen anions in $\mathrm{CeFeO}_{3}$, since oxygen vacancy within $\mathrm{CeFeO}_{3}$ is likely to be very low.

Based on the above findings, three possible causes for deactivation of ceria supported oxygen carriers can be identified: (i) formation of a stable $\mathrm{CeFeO}_{3}$ perovskite phase, (ii) decrease in surface area, and (iii) the enrichment and segregation of iron oxides on the oxygen carrier surface. While mechanism (i) may partially account for the decrease in activity, it is not the primary cause since one would expect the redox activity of the oxygen carrier to stabilize once $\mathrm{CeFeO}_{3}$ is formed. This; however, is not observed (Figure S8). In order to determine whether surface area loss (mechanism ii) is the main deactivation factor, a low surface area $\mathrm{Fe}_{2} \mathrm{O}_{3}: \mathrm{CeO}_{2}$ is prepared by sintering an identical sample at $1100^{\circ} \mathrm{C}$ for 8 hours. The $300{ }^{\circ} \mathrm{C}$ increase in sintering temperature compared to the reference sample leads to an oxygen carrier sample with lower initial surface area.

Activity comparisons of the low sintering temperature $\left(800^{\circ} \mathrm{C}\right)$ and high sintering temperature $\left(1,100^{\circ} \mathrm{C}\right)$ samples are shown in Figure 9. With respect to the first reduction cycle, the $1,100^{\circ} \mathrm{C}$ sintered oxygen carrier has almost 6 times lower activity (for 33\% conversion) compared to the $800^{\circ} \mathrm{C}$ sintered sample, indicating that surface area plays a role in sample activity. While the $800^{\circ} \mathrm{C}$ sintered sample deactivates from the $5^{\text {th }}$ cycle onwards, the $1,100{ }^{\circ} \mathrm{C}$ sintered sample activates over the first 10 cycles by approximately a factor of 3 before deactivating at a slower pace. The initial activation is resulted from the formation of cracks and pores from the thoroughly sintered oxygen carrier. Such activation-slow deactivation phenomena clearly indicate that loss of surface area during high temperature redox reactions is not the primary cause for deactivation.
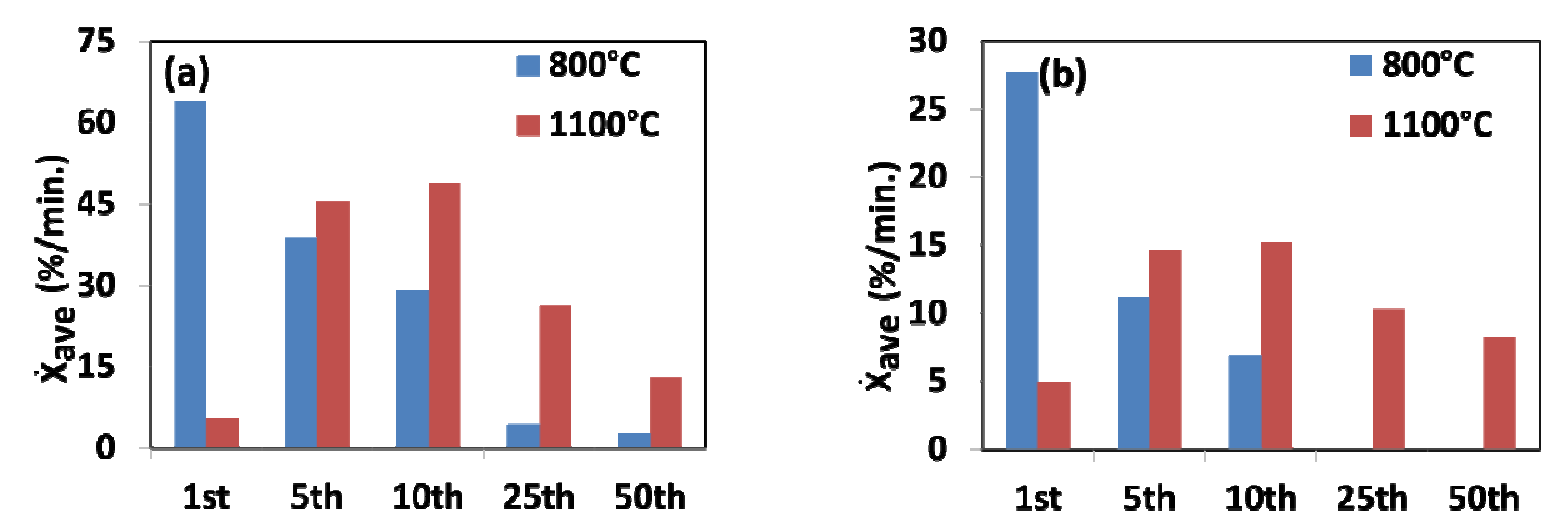

Figure 9- Average conversion rate $\left(\dot{X}_{\text {ave }}\right)$ to (a) $11 \%$ and (b) $33 \%$ conversion comparison of the $800^{\circ} \mathrm{C} 1,100^{\circ} \mathrm{C}$ sintered $\mathrm{CeO}_{2}$ supported $\mathrm{Fe}_{2} \mathrm{O}_{3}(6: 4)$ in $\mathrm{CH}_{4}$ at $900^{\circ} \mathrm{C}$ synthesized by a coprecipitation method. The lower sintered oxygen carrier does not achieve $33 \%$ conversion in the $25^{\text {th }}$ and $50^{\text {th }}$ cycles. 
To further validate the migration of $\mathrm{Fe}^{\mathrm{x}+}, \mathrm{Fe} / \mathrm{Ce}$ ratios are obtained for both the $1100^{\circ} \mathrm{C}$ 4:6 Fe:Ce oxygen carrier and $800^{\circ} \mathrm{C}$ 3:7 Fe:Ce oxygen carrier (see Figure S7 and Table S3). SEM and EDX scans of the $1,100^{\circ} \mathrm{C}$ sintered oxygen carrier indicate a more homogeneous starting material compared to the $800^{\circ} \mathrm{C}$ sintered sample. EDX scans on the $50^{\text {th }}$ cycle oxidized $1,100^{\circ} \mathrm{C}$ sample also show an enrichment of iron. The lower rate of iron phase segregation for the $1,100^{\circ} \mathrm{C}$ sample is likely to be responsible for the slower deactivation of the high temperature sintered sample. Figure 10 summarizes the relationship between oxygen carrier activity and near surface $\mathrm{Fe} / \mathrm{Ce}$ ratio for all three ceria supported iron oxides. As can be seen, surface enrichment of Fe occurs in all three ceria supported samples, leading to a general trend of lowering activity with increasing near surface $\mathrm{Fe} / \mathrm{Ce}$ ratio. Based on the above findings, it is concluded that iron oxide aggregation on the surface, through $\mathrm{Fe}^{\mathrm{x}+}$ migration, is the primary cause for the deactivation of ceria supported oxygen carriers. Aggregation of iron oxide causes deactivation through increased gaseous and solid-state diffusion resistances. Decrease in sample surface area, as observed in $800{ }^{\circ} \mathrm{C}$ sintered sample, is a consequence of iron migration/agglomeration as opposed to the primary cause for deactivation.

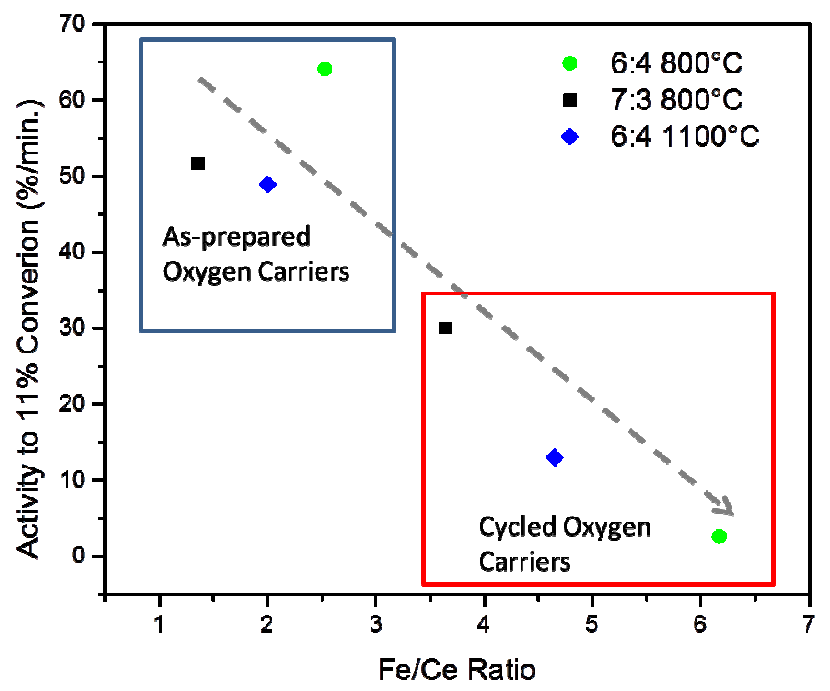

Figure 10- Comparison of the activity of $\mathrm{CeO}_{2}$ supported iron oxides versus the $\mathrm{Fe} / \mathrm{Ce}$ ratio on the surface. Cycle 5 and 50 data are used for the $1,100{ }^{\circ} \mathrm{C}$ sample. Cycle 1 and 50 data are used for the other samples.

\section{4 $\mathrm{MgAl}_{2} \mathrm{O}_{4}$ supported $\mathrm{Fe}_{2} \mathrm{O}_{3}$}

Unlike $\mathrm{CeO}_{2}, \mathrm{MgAl}_{2} \mathrm{O}_{4}$ supported oxygen carrier becomes more active for methane conversion as the number of cycles increase. Figure 11(a) and (b) illustrate the conversion rate of $\mathrm{MgAl}_{2} \mathrm{O}_{4}$ supported oxygen carrier in $\mathrm{H}_{2}$ and $\mathrm{CH}_{4}$, respectively. Interestingly, activity of the sample in $\mathrm{H}_{2}$ is found to decrease by $30 \%$ from cycle 2 to 10 while $\mathrm{CH}_{4}$ activity increases by $30 \%$ between cycle 2 and 5. To further investigate this fuel-dependent activation phenomenon, a second 
$\mathrm{MgAl}_{2} \mathrm{O}_{4}$ supported oxygen carrier with increased amount of iron oxide (6:4 instead of 3:7 weight ratio between $\mathrm{Fe}_{2} \mathrm{O}_{3}$ and $\mathrm{MgAl}_{2} \mathrm{O}_{4}$ ) sintered at $1,200^{\circ} \mathrm{C}$ is prepared. The sample is found to "activate" in methane at a faster rate, as shown in Figure 11 (c). Carbon formation for this sample based on sample weight gain, which tends to underestimate actual carbon formation, is much more severe than the $\mathrm{CeO}_{2}$ supported material.

XRD spectra of the oxygen carrier developed in Figure 11 (c) are shown in Figure 12. The phases are fairly consistent in the oxidized samples along with iron oxide crystallite size. The phase analysis of the reduced samples; however, presents significant difference over multiple redox cycles. Initially, the iron oxide is only reduced to $\mathrm{FeO}$ within the 10 minute reduction cycle; this is consistent with the low activity of the sample. It is also observed that Fe is partially substituted into the spinel structure of the support. As the activity of the oxygen carrier increases, a new iron carbide phase is observed. This indicates coke formation and increased degree of iron oxide reduction. In the meantime, BET surface area of the sample is found to increase by $15 \%$ over the 5 redox cycles. A summary of the surface area, crystallite sizes, and carbon formation are shown in Table 4. The PSDs of the $\mathrm{MgAl}_{2} \mathrm{O}_{4}$ supported oxygen carrier indicate an increase in meso-pore volumes with increasing number of redox cycles (See Figure S10).

Further characterization of the sample under TEM indicates notable carbon filaments in reduced oxygen carrier samples after multiple redox cycles (See Figure 13). While TEM images of the first cycle reduced sample display little carbon formation (See Figure S11), TEM images of $6^{\text {th }}$ cycle reduced sample illustrates grapheme layers covering the surface of the oxygen carrier and growing out in "thread" like filaments. Most of the hollow fiber strands can be categorized as filamentous carbon or multi-walled carbon nanotubes. These observations are in agreement with what was observed by Ermakova et. al.[65]

The nanotube growth on the sample has led to the breakage of active catalyst grains, i.e. iron, from the oxygen carrier surface, thereby compromising the structural integrity of the oxygen carrier. The deformation of the particle is due to growth of the filamentous carbon causing interstitial gaps within the oxygen carrier. These effects correspond well to surface area increase of the sample. Visual inspection of the sample also indicates significant expansion of the oxygen carrier sample over multiple redox cycles. In contrast, deactivation of the same sample is observed in $\mathrm{H}_{2}$ due to the lack of carbon formation and hence continued sintering of the oxygen carrier. It should be noted, while high redox activity of oxygen carriers is a sought after feature in chemical looping processes. Physical disintegration of the oxygen carrier can be detrimental to CLC, which is operated in fluidized bed and/or moving bed reactors. Based on the above discussions, formation of filamentous carbon on the $\mathrm{MgAl}_{2} \mathrm{O}_{4}$ supported oxygen carrier is the primary cause for its activation phenomena in $\mathrm{CH}_{4}-\mathrm{O}_{2}$ redox cycles and the corresponding surface area increase through structural disintegration. 

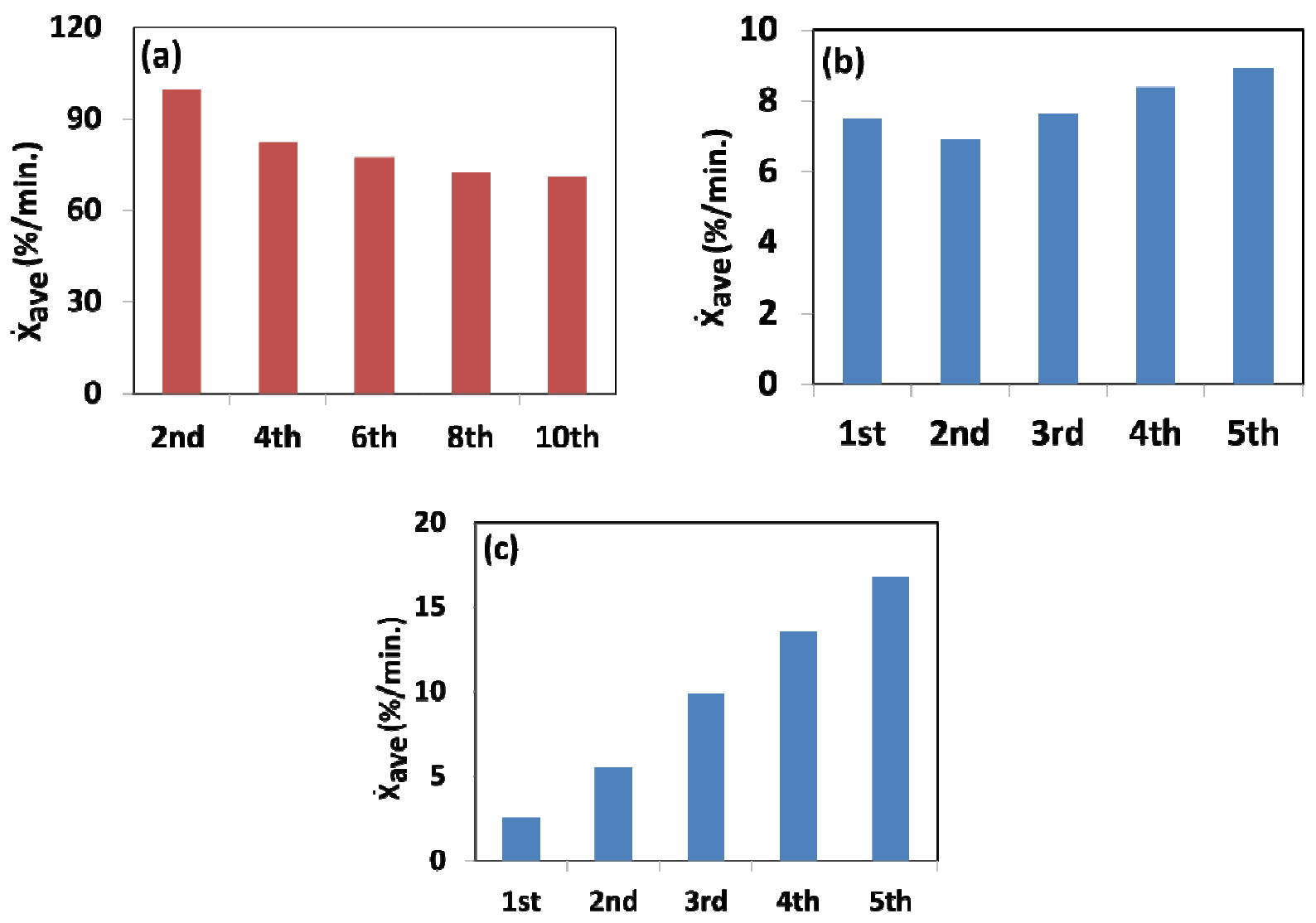

Figure 11- Average conversion rate $\left(\dot{X}_{\text {ave }}\right)(\% / \mathrm{min})$ to $33 \%$ conversion of the $\mathrm{MgAl}_{2} \mathrm{O}_{4}$ supported $\mathrm{Fe}_{2} \mathrm{O}_{3}$ (7:3) via SSR tested in (a) 10 cycles with $\mathrm{H}_{2}$ and (b) 5-cycles with $\mathrm{CH}_{4}$ and (c) 5 cycles in $\mathrm{CH}_{4}$ of $1200^{\circ} \mathrm{C}$ sintered $4: 6 \mathrm{Fe}_{2} \mathrm{O}_{3}: \mathrm{MgAl}_{2} \mathrm{O}_{4}$ at a reaction temperature of $900^{\circ} \mathrm{C}$.
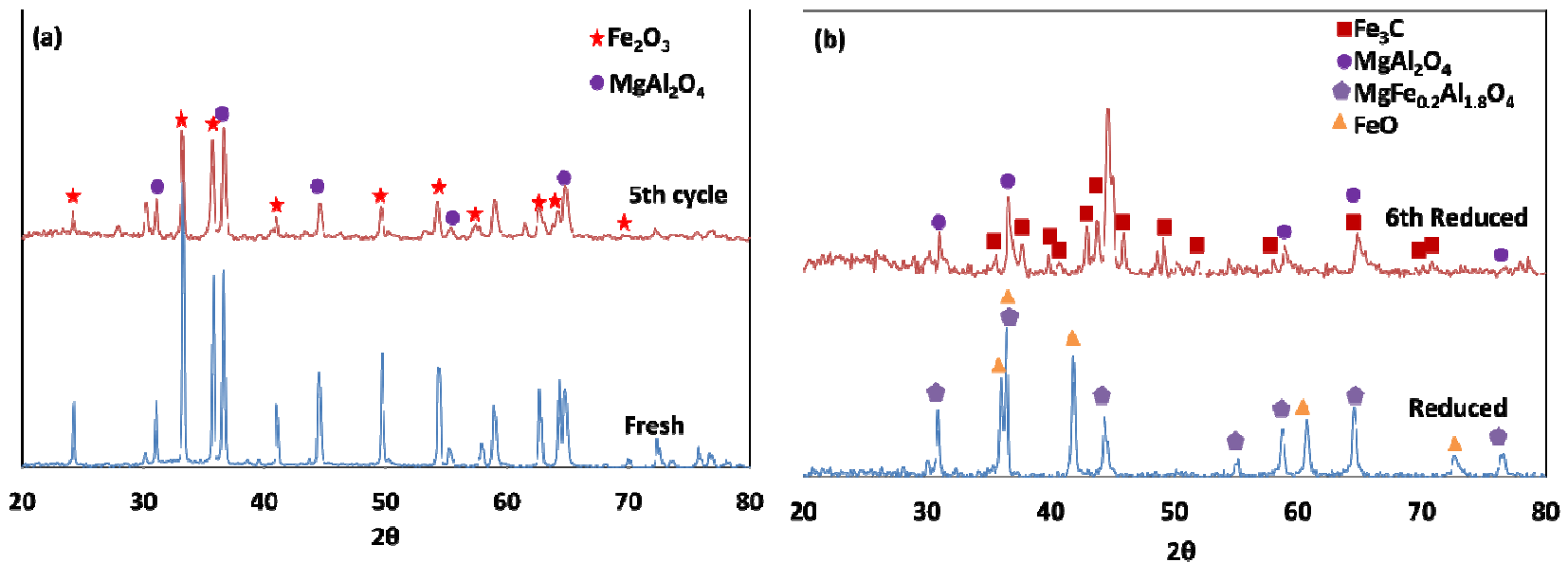

Figure 12- XRD of the (a) fresh and 5th oxidized samples of Fe2O3 MgAl2O4 SSR sample and (b) of the $1^{\text {st }}$ and $6^{\text {th }}$ reduced oxygen carrier. 
Table 4. Summary of carbon formation, crystallite sizes, and BET surface areas of the $\mathrm{MgAl}_{2} \mathrm{O}_{4}: \mathrm{Fe}_{2} \mathrm{O}_{3}(4: 6)$ oxygen carrier

\begin{tabular}{|l|c|c|}
\hline & Fresh $\left(2^{\text {nd }}\right.$ reduced $)$ & $5^{\text {th }}$ \\
\hline $\begin{array}{l}\text { Carbon Formation }(\%)(60 \\
\text { minute reduction) }\end{array}$ & 45.0 & 43.5 \\
\hline $\begin{array}{l}\text { BET Surface Area (oxidized } \\
\text { samples) }\left(\mathrm{m}^{2} / \mathrm{gm}\right)\end{array}$ & 3.8 & 4.4 \\
\hline Crystallite Size $\mathrm{MgAl}_{2} \mathrm{O}_{4}(\AA)$ & 290 & 400 \\
\hline Crystallite ${\mathrm{Size} \mathrm{Fe}_{2} \mathrm{O}_{3}(\AA)}^{\AA}$ & 280 & 280 \\
\hline
\end{tabular}
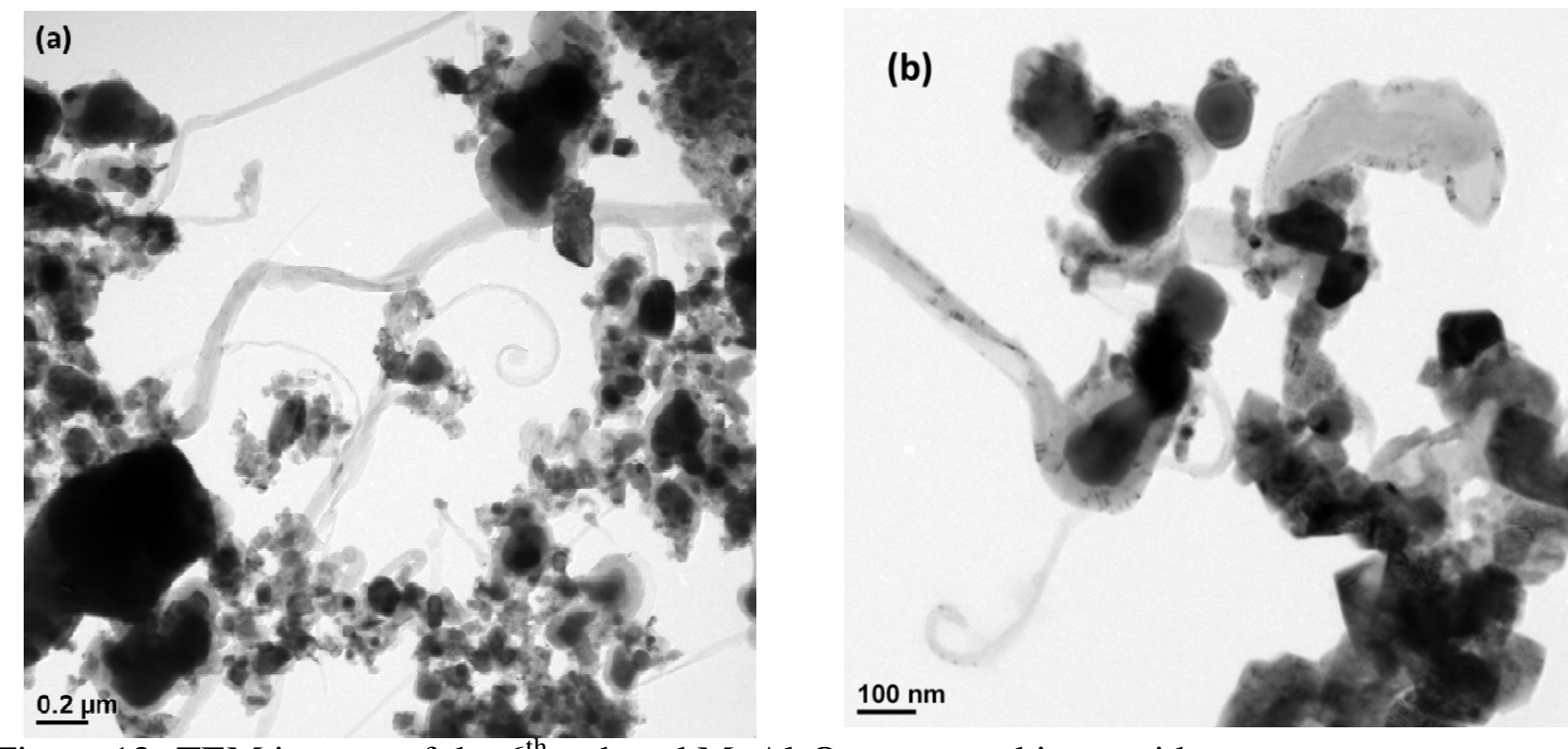

Figure 13- TEM images of the $6^{\text {th }}$ reduced $\mathrm{MgAl}_{2} \mathrm{O}_{4}$ supported iron oxide.

\section{Conclusion}

The present study investigates supported iron oxides with distinct structural and conductive properties for chemical looping applications. While oxygen carriers supported by mixedconductive perovskite $\left(\mathrm{Ca}_{\mathrm{x}} \mathrm{Sr}_{1-\mathrm{x}} \mathrm{Ti}_{\mathrm{y}} \mathrm{Ni}_{1-\mathrm{y}} \mathrm{O}_{3-\delta}\right)$ and fluorite $\left(\mathrm{CeO}_{2}\right)$ both exhibited high initial activity, $\mathrm{CeO}_{2}$ supported iron oxide notably deactivates with increasing number of redox cycles. To compare, perovskite supported iron oxide only slightly deactivates within the first 5 redox cycles, resulting from substitution of $\mathrm{Ni}^{2+}$ on perovskite B-site by $\mathrm{Fe}^{3+}$. Complete substitution of 
$\mathrm{Ni}^{2+}$ leads to stable redox activity. XRD, SEM, and EDX analyses indicate that continued deactivation of ceria supported iron oxide in methane, under deep redox cycles, can be explained by iron migration, enrichment, and agglomeration on the sample surface over multiple redox cycles. The inability for $\mathrm{Fe}$ to stabilize inside the $\mathrm{CeO}_{2}$ supported particle has led to large, segregated iron oxide on the surface. This causes decreased accessibility of $\mathrm{O}^{2-}$ to gaseous fuels.

Unlike the mixed-conductor supported oxygen carriers, $\mathrm{MgAl}_{2} \mathrm{O}_{4}$ supported iron oxide is found to activate over $\mathrm{CH}_{4}-\mathrm{O}_{2}$ redox cycles but deactivate in $\mathrm{H}_{2}-\mathrm{O}_{2}$ redox cycles. Further investigation by TEM confirms significant carbon formation during $\mathrm{CH}_{4}-\mathrm{O}_{2}$ cycles. The graphitic carbon appears to cover the oxygen carrier where it threads out into filamentous carbon or multi-walled carbon nanotubes. The nanotube growth on the sample has led to breakage of active catalyst grains, i.e. iron, from the oxygen carrier surface, thereby compromising the structural integrity of the oxygen carrier while increasing its surface area and meso-pore volume. While the deformation of the oxygen carrier can significantly enhance the activity of the oxygen carriers, it leads to undesired structural degradation of the oxygen carrier over multiple redox cycles.

From an oxygen carrier design and optimization standpoint, supports that stabilize iron (oxide) grains in a mixed-conductive matrix can result in highly active oxygen carriers that exhibit stable activity and structural integrity. One should avoid supports that promote outwards diffusion of $\mathrm{Fe}^{\mathrm{x}+}$ or carbon filament formation since such supports could lead to oxygen carrier deactivation or apparent "activation" through structural expansion/disintegration.

\section{Acknowledgements}

This work is supported by the U.S. National Science Foundation under Award (CBET-1254351) and the U.S. Department of Energy under Award (FE0011247). The authors acknowledge the use of the Analytical Instrumentation Facility (AIF) at North Carolina State University, which is supported by the State of North Carolina and the National Science Foundation. We would also like to acknowledge Amy Stewart for her help in conducting some of the reactivity experiments.

\section{References}

[1] C. Bessou, F. Ferchaud, B. Gabrielle, B. Mary, Biofuels, Greenhouse Gases and Climate Change, in: E. Lichtfouse, M. Hamelin, M. Navarrete, P. Debaeke (Eds.), Sustain. Agric. Vol. 2, Springer Netherlands, Dordrecht, 2011: pp. 365-468.

[2] D.A. Lashof, D.R. Ahuja, Relative Contributions of Greenhouse Gas Emissions to Global Warming, Nature. 344 (1990) 529-531.

[3] J. Adanez, A. Abad, F. Garcia-Labiano, P. Gayan, L.F. de Diego, Progress in ChemicalLooping Combustion and Reforming Technologies, Prog. Energ. Combust. 38 (2012) 215282.

[4] L.-S. Fan, Chemical Looping Systems for Fossil Energy Conversions, 2010. 
[5] L.-S. Fan, F. Li, Chemical Looping Technology and Its Fossil Energy Conversion Applications, Ind. Eng. Chem. Res. 49 (2010) 10200-10211.

[6] L.-S. Fan, F. Li, Conversion of Carbonaceous Fuels Into Carbon Free Energy Carriers, EP2406545 A2, 2012.

[7] L.-S. Fan, L. Zeng, W. Wang, S. Luo, Chemical Looping Processes for $\mathrm{CO}_{2}$ Capture and Carbonaceous Fuel Conversion - prospect and opportunity, Energ. Environ. Sci. 5 (2012) 7254.

[8] M.M. Hossain, H.I. de Lasa, Chemical-Looping Combustion (CLC) for Inherent Separations-A Review, Chem. Eng. Sci. 63 (2008) 4433-4451.

[9] A. Lyngfelt, M. Johansson, T. Mattisson, Chemical-Looping Combustion - Status Of Development, In: Proceedings of the $9^{\text {th }}$ International Conference on Circulating Fluidized Beds. 2008.

[10] F. Li, L.-S. Fan, Clean Coal Conversion Processes - Progress and Challenges, Energ. Environ. Sci. 1 (2008) 248.

[11] J. Adánez, L.F. de Diego, F. García-Labiano, P. Gayán, A. Abad, J.M. Palacios, Selection of Oxygen Carriers for Chemical-Looping Combustion, Energ. Fuel. 18 (2004) 371-377.

[12] K.-S. Kang, C.-H. Kim, K.-K. Bae, W.-C. Cho, S.-H. Kim, C.-S. Park, Oxygen-Carrier Selection and Thermal Analysis of the Chemical-Looping Process for Hydrogen Production, Int. J. Hydrogen Energ. 35 (2010) 12246-12254.

[13] A. Lyngfelt, Oxygen Carriers for Chemical Looping Combustion - 4,000 h of Operational Experience, Oil Gas Sci. Technol. 66 (2011) 161-172.

[14] T.M. Paul Cho, Comparison of Iron-, Nickel-, Copper- and Manganese-Based Oxygen Carriers for Chemical-Looping Combustion, Fuel. (2004) 1215-1225.

[15] K. Shah, B. Moghtaderi, T. Wall, Selection of Suitable Oxygen Carriers for Chemical Looping Air Separation: A Thermodynamic Approach, Energ. Fuel. 26 (2012) 2038-2045.

[16] F. He, N. Galinsky, F. Li, Chemical Looping Gasification of Solid Fuels Using Bimetallic Oxygen Carrier Particles - Feasibility Assessment and Process Simulations, Int. J. Hydrogen Energ. 38 (2013) 7839-7854.

[17] S. Roux, A. Bensakhria, G. Antonini, Study and Improvement of the Regeneration of Metallic Oxides Used as Oxygen Carriers for a New Combustion Process, Int. J. Chem. React. Eng. 4 (2006).

[18] E. Jerndal, H. Leion, L. Axelsson, T. Ekvall, M. Hedberg, K. Johansson, et al., Using LowCost Iron-Based Materials as Oxygen Carriers for Chemical Looping Combustion, Oil Gas Sci. Technol. 66 (2011) 235-248.

[19] K. Svoboda, G. Slowinski, J. Rogut, D. Baxter, Thermodynamic Possibilities and Constraints for Pure Hydrogen Production by Iron Based Chemical Looping Process at Lower Temperatures, Energ. Convers. Manage. 48 (2007) 3063-3073.

[20] J. Adanez, F. García-Labiano, L.F. de Diego, P. Gayán, J. Celaya, A. Abad, Characterization of Oxygen Carriers for Chemical-Looping Combustion, In: Greenhouse Gas Control Technologies 7, Elsevier Science Ltd, Oxford, 2005: pp. 105-113.

[21] B.M. Corbella, J.M. Palacios, Titania-Supported Iron Oxide as Oxygen Carrier for Chemical-Looping Combustion of Methane, Fuel. 86 (2007) 113-122.

[22] M. Johansson, T. Mattisson, A. Lyngfelt, Investigation of $\mathrm{Fe}_{2} \mathrm{O}_{3}$ with $\mathrm{MgAl}_{2} \mathrm{O}_{4}$ for Chemical-Looping Combustion, Ind. Eng. Chem. Res. 43 (2004) 6978-6987.

[23] X. Zhu, Y. Wei, H. Wang, K. Li, Ce-Fe Oxygen Carriers for Chemical-Looping Steam Methane Reforming, Int. J. Hydrogen Energ. 38 (2013) 4492-4501. 
[24] Q. Zafar, T. Mattisson, B. Gevert, Redox Investigation of Some Oxides of Transition-State Metals Ni, $\mathrm{Cu}, \mathrm{Fe}$, and $\mathrm{Mn}$ Supported on $\mathrm{SiO}_{2}$ and $\mathrm{MgAl}_{2} \mathrm{O}_{4}$, Energ. Fuel. 20 (2006) 34-44.

[25] K. Li, H. Wang, Y. Wei, D. Yan, Transformation of Methane into Synthesis Gas Using the Redox Property of Ce-Fe Mixed Oxides: Effect of Calcination Temperature, Int. J. Hydrogen Energ. 36 (2011) 3471-3482.

[26] A. Hedayati, A.-M. Azad, M. Rydén, H. Leion, T. Mattisson, Evaluation of Novel CeriaSupported Metal Oxides As Oxygen Carriers for Chemical-Looping Combustion, Ind. Eng. Chem. Res. 51 (2012) 12796-12806.

[27] F. Li, H.R. Kim, D. Sridhar, F. Wang, L. Zeng, J. Chen, et al., Syngas Chemical Looping Gasification Process: Oxygen Carrier Particle Selection and Performance, Energ. Fuel. 23 (2009) 4182-4189.

[28] J. Adánez, A. Cuadrat, A. Abad, P. Gayán, L.F. de Diego, F. García-Labiano, Ilmenite Activation during Consecutive Redox Cycles in Chemical-Looping Combustion, Energ. Fuel. 24 (2010) 1402-1413.

[29] M.F. Bleeker, H.J. Veringa, S.R.A. Kersten, Deactivation of Iron Oxide Used in the SteamIron Process to Produce Hydrogen, Appl. Catal. A-Gen. 357 (2009) 5-17.

[30] A. Cuadrat, A. Abad, J. Adánez, L.F. de Diego, F. García-Labiano, P. Gayán, Behavior of Ilmenite as Oxygen Carrier in Chemical-Looping Combustion, Fuel Process. Technol. 94 (2012) 101-112.

[31] T. Mattisson, M. Johansson, A. Lyngfelt, Multicycle Reduction and Oxidation of Different Types of Iron Oxide Particles Application to Chemical-Looping Combustion, Energ Fuel. 18 (2004) 628-637.

[32] F. Li, S. Luo, Z. Sun, X. Bao, L.-S. Fan, Role of Metal Oxide Support in Redox Reactions of Iron Oxide for Chemical Looping Applications: Experiments and Density Functional Theory Calculations, Energ Environ. Sci. 4 (2011) 3661.

[33] F. Li, Z. Sun, S. Luo, L.-S. Fan, Ionic Diffusion in the Oxidation of Iron-Effect of Support and Its Implications to Chemical Looping Applications, Energ. Environ. Sci. 4 (2011) 876.

[34] N.L. Galinsky, Y. Huang, A. Shafiefarhood, F. Li, Iron Oxide with Facilitated $\mathrm{O}^{2-}$ Transport for Facile Fuel Oxidation and $\mathrm{CO}_{2}$ Capture in a Chemical Looping Scheme, ACS Sustain. Chem. Eng. 1 (2013) 364-373.

[35] A. Shafiefarhood, N. Galinsky, Y. Huang, Y. Chen, F. Li, Fe2O3@LaxSr1-xFeO3 CoreShell Redox Catalyst for Methane Partial Oxidation, ChemCatChem. 6 (2014) 790.

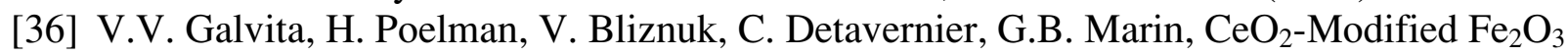
for $\mathrm{CO}_{2}$ Utilization via Chemical Looping, Ind. Eng. Chem. Res. 52 (2013) 8416-8426.

[37] X. Zhu, H. Wang, Y. Wei, K. Li, X. Cheng, Hydrogen and Syngas Production from TwoStep Steam Reforming of Methane Using $\mathrm{CeO}_{2}$ as Oxygen Carrier, J. Nat. Gas Chem. 20 (2011) 281-286.

[38] X. Zhu, H. Wang, Y. Wei, K. Li, X. Cheng, Reaction Characteristics of Chemical-Looping Steam Methane Reforming over a $\mathrm{Ce}-\mathrm{ZrO}_{2}$ Solid Solution Oxygen Carrier, Mendeleev Commun. 21 (2011) 221-223.

[39] Galvita, V., Hempel, T., Lorenz, H., Rihko-Struckmann, L.K., Sundmacher, K., Deactivation of Modified Iron Oxide Materials in the Cyclic Water Gas Shift Process for CO-Free Hydrogen Production, Ind. Eng. Chem. Res. 47 (2008) 303-310.

[40] S. Bhavsar, G. Veser, Bimetallic Fe-Ni Oxygen Carriers for Chemical Looping Combustion, Ind. Eng. Chem. Res. 52 (2013) 15342-15352. doi:10.1021/ie400612g. 
[41] Z. Gu, K. Li, H. Wang, Y. Wei, D. Yan, T. Qiao, Syngas production from methane over $\mathrm{CeO} 2-\mathrm{Fe} 2 \mathrm{O} 3$ mixed oxides using a chemical-looping method, Kinet. Catal. 54 (2013) 326333. doi:10.1134/S002315841303004X.

[42] F. He, Y. Wei, H. Li, H. Wang, Synthesis Gas Generation by Chemical-Looping Reforming Using Ce-Based Oxygen Carriers Modified with $\mathrm{Fe}, \mathrm{Cu}$, and Mn Oxides, Energy Fuels. 23 (2009) 2095-2102. doi:10.1021/ef800922m.

[43] K. Li, H. Wang, Y. Wei, M. Liu, Catalytic performance of cerium iron complex oxides for partial oxidation of methane to synthesis gas, J. Rare Earths. 26 (2008) 705-710. doi:10.1016/S1002-0721(08)60167-2.

[44] K. Li, H. Wang, Y. Wei, D. Yan, Direct conversion of methane to synthesis gas using lattice oxygen of CeO2-Fe2O3 complex oxides, Chem. Eng. J. 156 (2010) 512-518. doi:10.1016/j.cej.2009.04.038.

[45] K. Li, H. Wang, Y. Wei, D. Yan, Syngas production from methane and air via a redox process using Ce-Fe mixed oxides as oxygen carriers, Appl. Catal. B Environ. 97 (2010) 361-372. doi:10.1016/j.apcatb.2010.04.018.

[46] Y. Wei, H. Wang, K. Li, Ce-Fe-O mixed oxide as oxygen carrier for the direct partial oxidation of methane to syngas, J. Rare Earths. 28 (2010) 560-565. doi:10.1016/S10020721(09)60154-X.

[47] X. Zhu, K. Li, Y. Wei, H. Wang, L. Sun, Chemical-Looping Steam Methane Reforming over a $\mathrm{CeO}_{2}-\mathrm{Fe}_{2} \mathrm{O}_{3}$ Oxygen Carrier: Evolution of Its Structure and Reducibility, Energy Fuels. 28 (2014) 754-760. doi:10.1021/ef402203a.

[48] M. Arjmand, A.-M. Azad, H. Leion, A. Lyngfelt, T. Mattisson, Prospects of $\mathrm{Al}_{2} \mathrm{O}_{3}$ and $\mathrm{MgAl}_{2} \mathrm{O}_{4}$-Supported $\mathrm{CuO}$ Oxygen Carriers in Chemical-Looping Combustion (CLC) and Chemical-Looping with Oxygen Uncoupling (CLOU), Energ. Fuel. 25 (2011) 5493-5502.

[49] J.-I. Baek, J.-W. Kim, J.B. Lee, T.H. Eom, J. Ryu, C.K. Ryu, et al., Effects of Support on the Performance of NiO-Based Oxygen Carriers, Oil Gas Sci. Technol. 66 (2011) 223-234.

[50] S.-C. Baek, J.-W. Bae, J.Y. Cheon, K.-W. Jun, K.-Y. Lee, Combined Steam and Carbon Dioxide Reforming of Methane on $\mathrm{Ni} / \mathrm{MgAl}_{2} \mathrm{O}_{4}$ : Effect of $\mathrm{CeO}_{2}$ Promoter to Catalytic Performance, Catal. Lett. 141 (2010) 224-234.

[51] Q. Zafar, A. Abad, T. Mattisson, B. Gevert, Reaction Kinetics of Freeze-Granulated $\mathrm{NiO} / \mathrm{MgAl}_{2} \mathrm{O}_{4}$ Oxygen Carrier Particles for Chemical-Looping Combustion, Energ. Fuel. 21 (2007) 610-618.

[52] S. Wang, G. Wang, F. Jiang, M. Luo, H. Li, Chemical Looping Combustion of Coke Oven Gas by using $\mathrm{Fe}_{2} \mathrm{O}_{3} / \mathrm{CuO}$ with $\mathrm{MgAl}_{2} \mathrm{O}_{4}$ as Oxygen Carrier, Energ. Environ. Sci. 3 (2010) 1353.

[53] K. Li, H. Wang, Y. Wei, M. Liu, Preparation and Characterization of $\mathrm{Ce}_{1-x} \mathrm{Fe}_{\mathrm{x}} \mathrm{O}_{2}$ Complex Oxides and Its Catalytic Activity for Methane Selective Oxidation, J. Rare Earth. 26 (2008) 245-249.

[54] T. Hayakawa, H. Harihara, A.G. Andersen, A.P.E. York, K. Suzuki, H. Yasuda, et al., A Sustainable Catalyst for the Partial Oxidation of Methane to Syngas: $\mathrm{Ni} / \mathrm{Ca}_{1-\mathrm{x}} \mathrm{Sr}_{\mathrm{x}} \mathrm{TiO}_{3}$, Prepared In Situ from Perovskite Precursors, Angew. Chem. Int. Edit. 35 (1996) 192-195.

[55] T. Mendiara, J.M. Johansen, R. Utrilla, P. Geraldo, A.D. Jensen, P. Glarborg, Evaluation of Different Oxygen Carriers for Biomass Tar Reforming (I): Carbon deposition in Experiments with Toluene, Fuel. 90 (2011) 1049-1060. 
[56] T. Mendiara, J.M. Johansen, R. Utrilla, A.D. Jensen, P. Glarborg, Evaluation of Different Oxygen Carriers for Biomass Tar Reforming (II): Carbon Deposition in Experiments with Methane and Other Gases, Fuel. 90 (2011) 1370-1382.

[57] Y. Zhao, F. Shadman, Reduction of Ilmenite with Hydrogen, Ind. Eng. Chem. Res. 30 (1991) 2080-2087.

[58] P. Cho, T. Mattisson, A. Lyngfelt, Carbon Formation on Nickel and Iron Oxide-Containing Oxygen Carriers for Chemical-Looping Combustion, Ind. Eng. Chem. Res. 44 (2005) 668676.

[59] P. Debokx, The Formation of Filamentous Carbon on Iron and Nickel Catalysts I. Thermodynamics, J. Catal. 96 (1985) 454-467.

[60] A. Kock, The Formation of Filamentous Carbon on Iron and Nickel Catalysts II. Mechanism, J. Catal. 96 (1985) 468-480.

[61] E.T. Turkdogan, J.V. Vinters, Gaseous reduction of iron oxides: Part I. Reduction of hematite in hydrogen, Metall. Mater. Trans. B. 2 (1971) 3175-3188.

[62] J. Smith, T. Norby, Cation Self-Diffusion in $\mathrm{LaFeO}_{3}$ Measured by the Solid State Reaction Method, Solid State Ionics 177 (2006) 639-646.

[63] A. Chroneos, R.V. Vovk, I.L. Goulatis, L.I. Goulatis, Oxygen Transport in Perovskite and Related Oxides: A Brief Review, J. Alloy. Compd. 494 (2010) 190-195.

[64] J.L. Routbort, S.J. Rothman, B.K. Flandermeyer, L.J. Nowicki, J.E. Baker, Oxygen Diffusion in $\mathrm{La}_{2-\mathrm{x}} \mathrm{Sr}_{\mathrm{x}} \mathrm{CuO}_{4-\mathrm{y}}$, J. Mater. Res. 3 (2011) 116-121.

[65] M. Ermakova, Decomposition of Methane over Iron Catalysts at the Range of Moderate Temperatures: The Influence of Structure of the Catalytic Systems and the Reaction Conditions on the Yield of Carbon and Morphology of Carbon Filaments, J. Catal. 201 (2001) 183-197. 


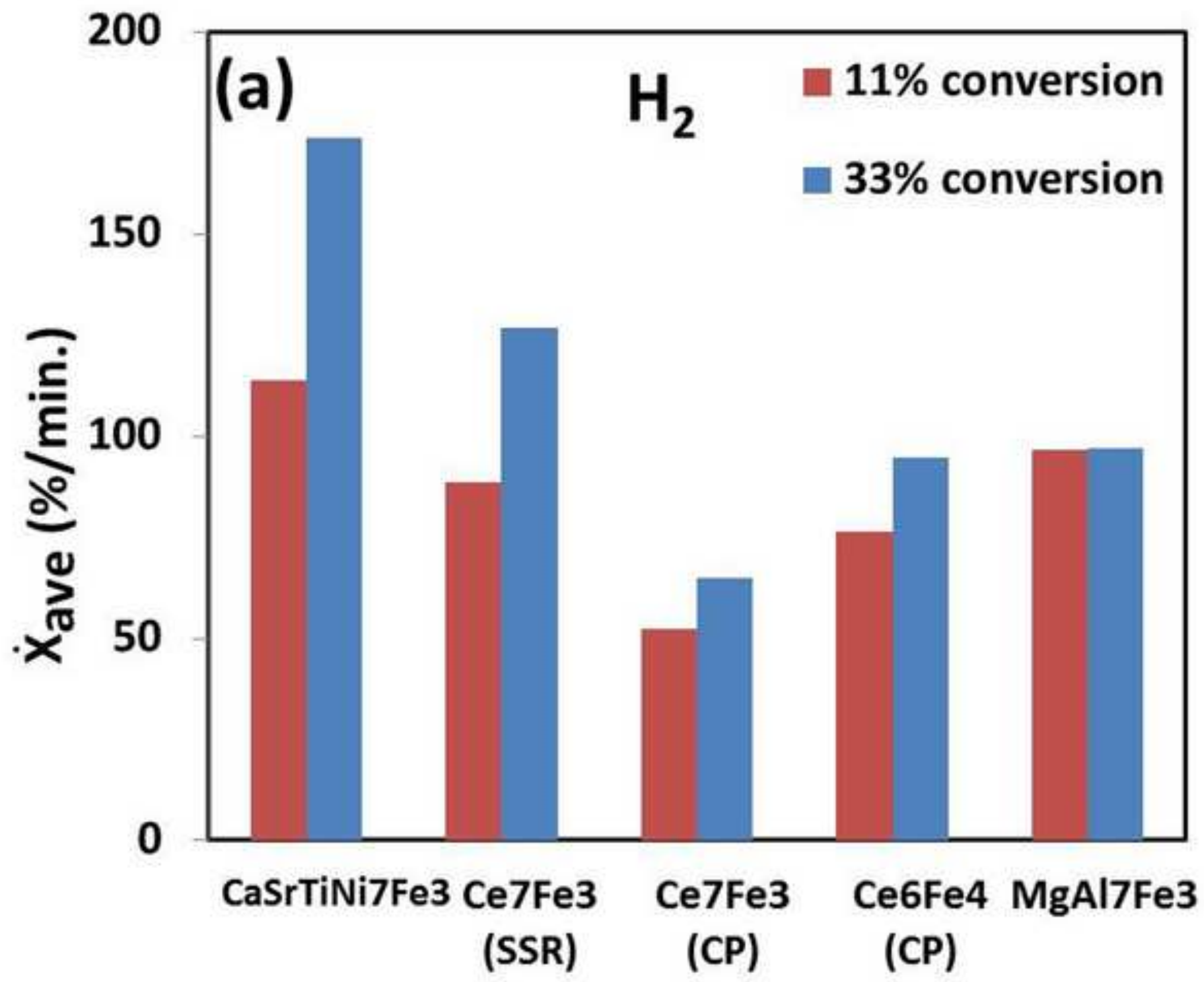




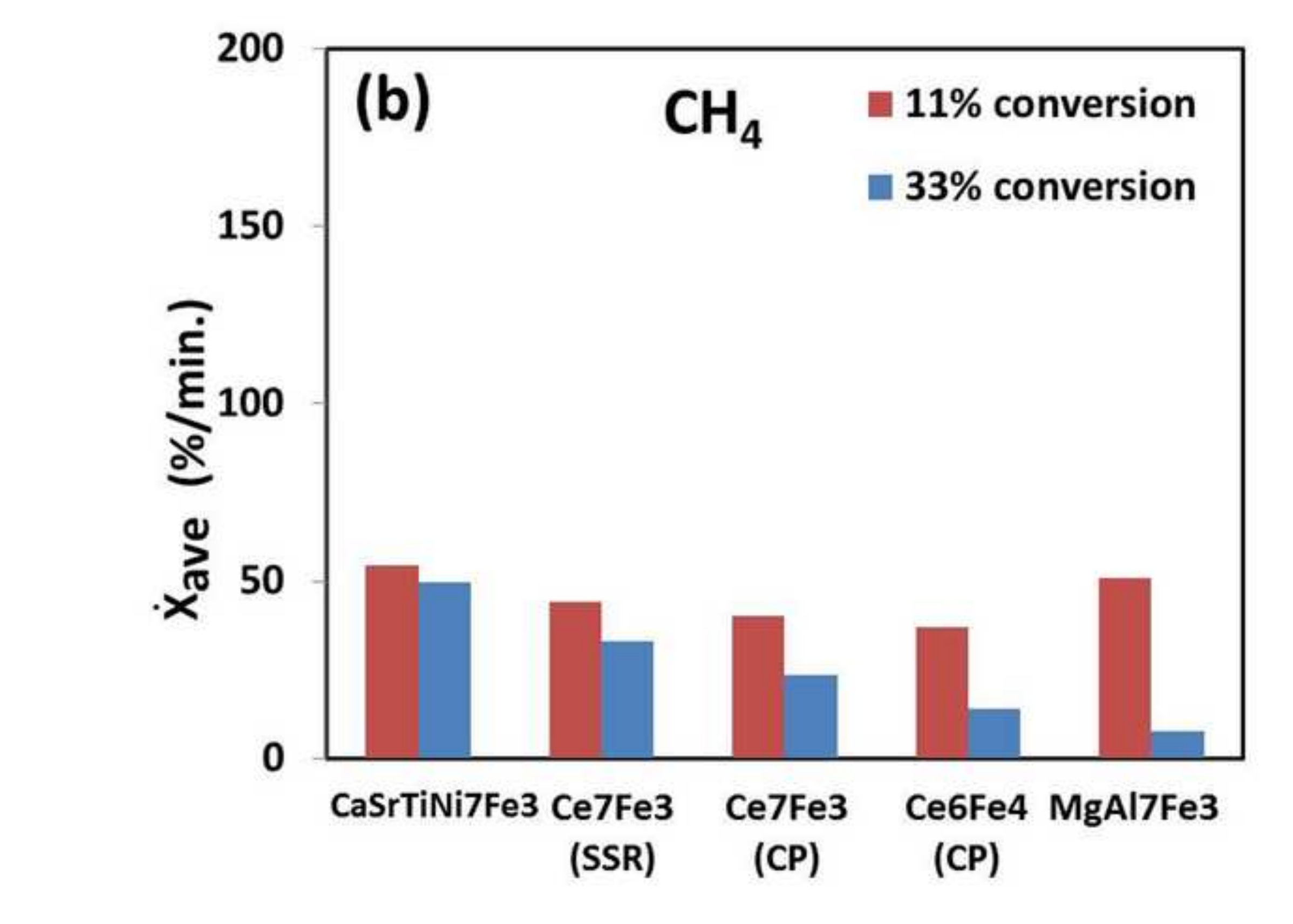

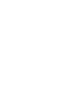

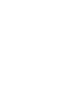

.

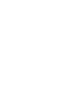

.
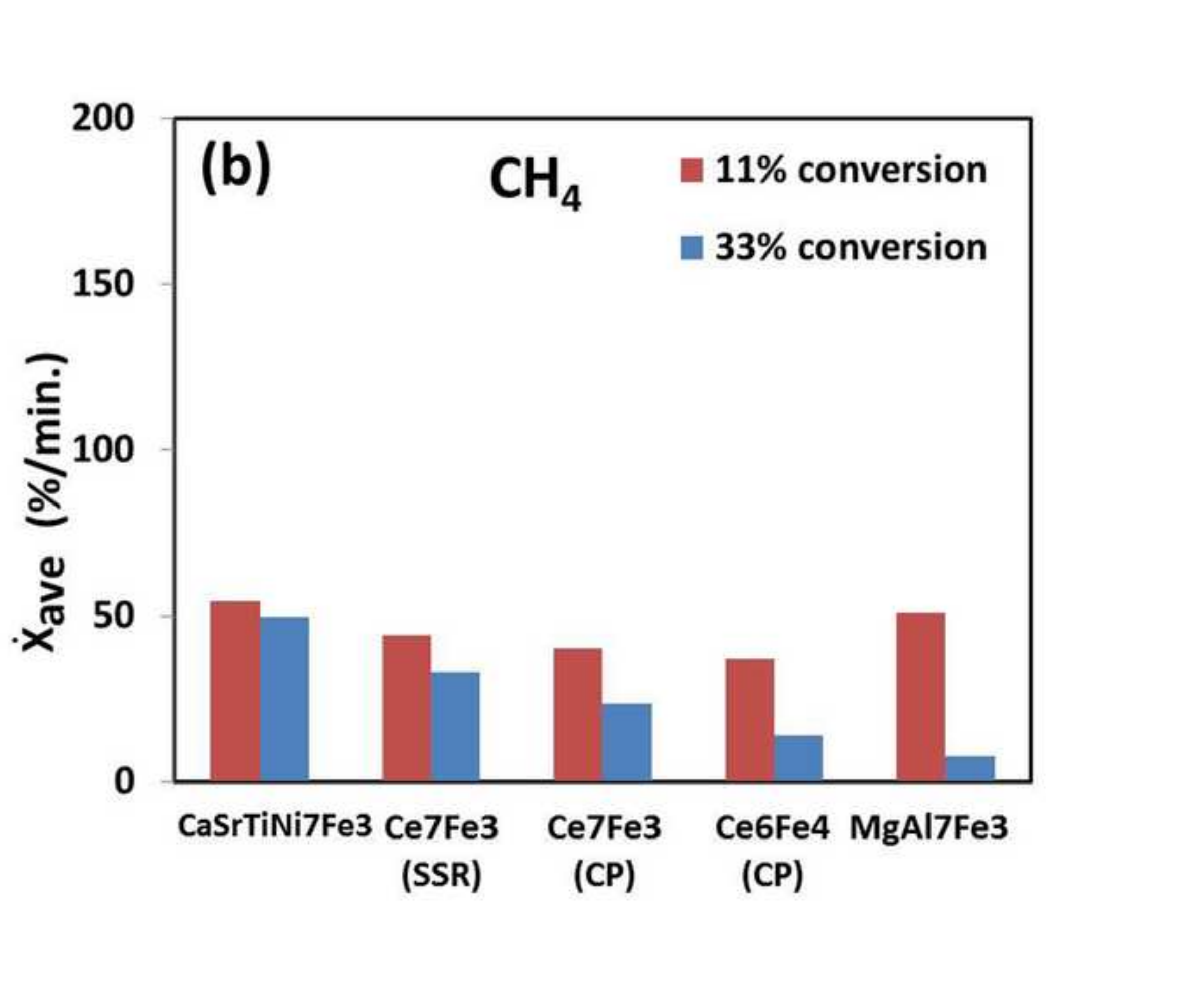

.

.




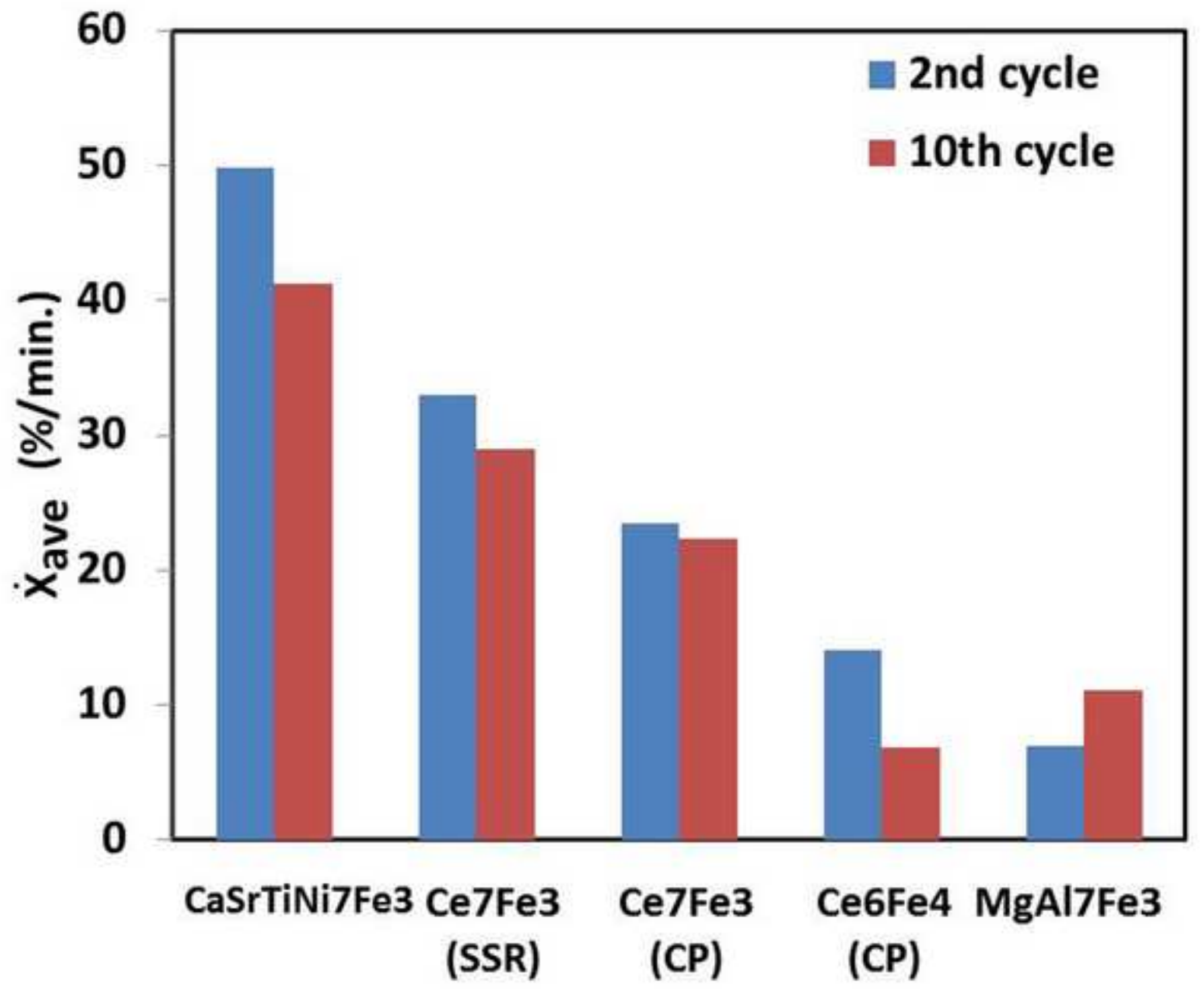




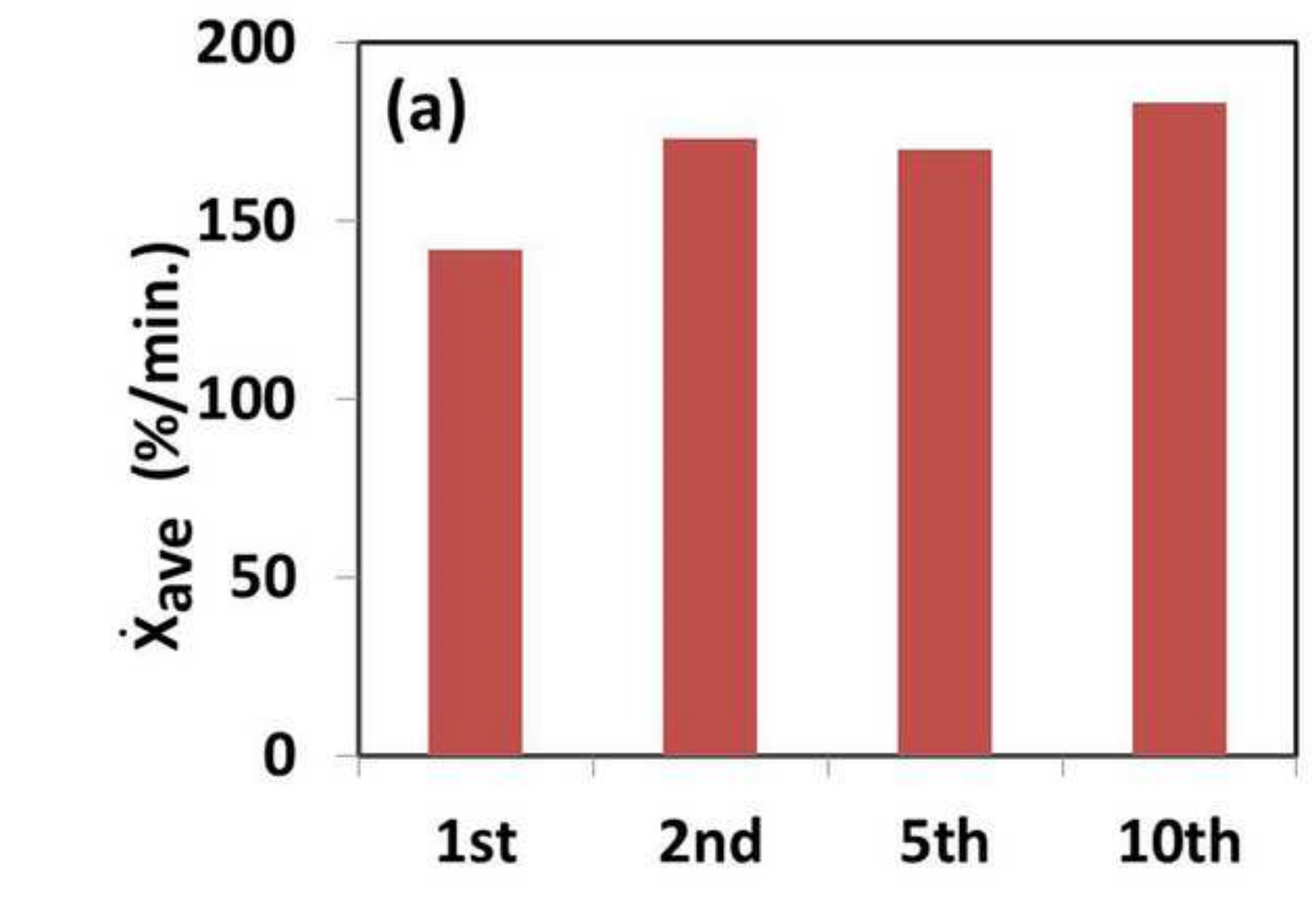




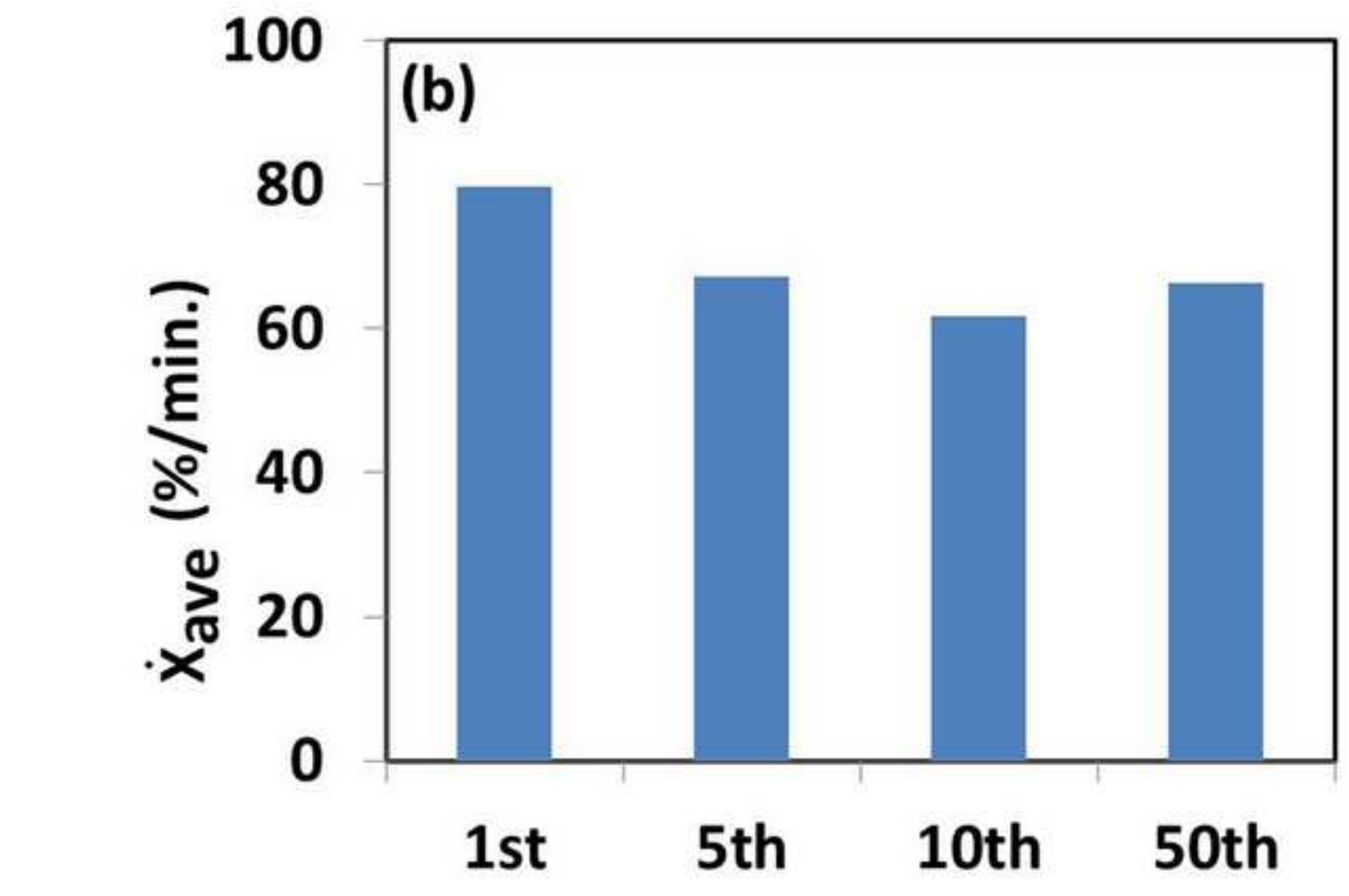




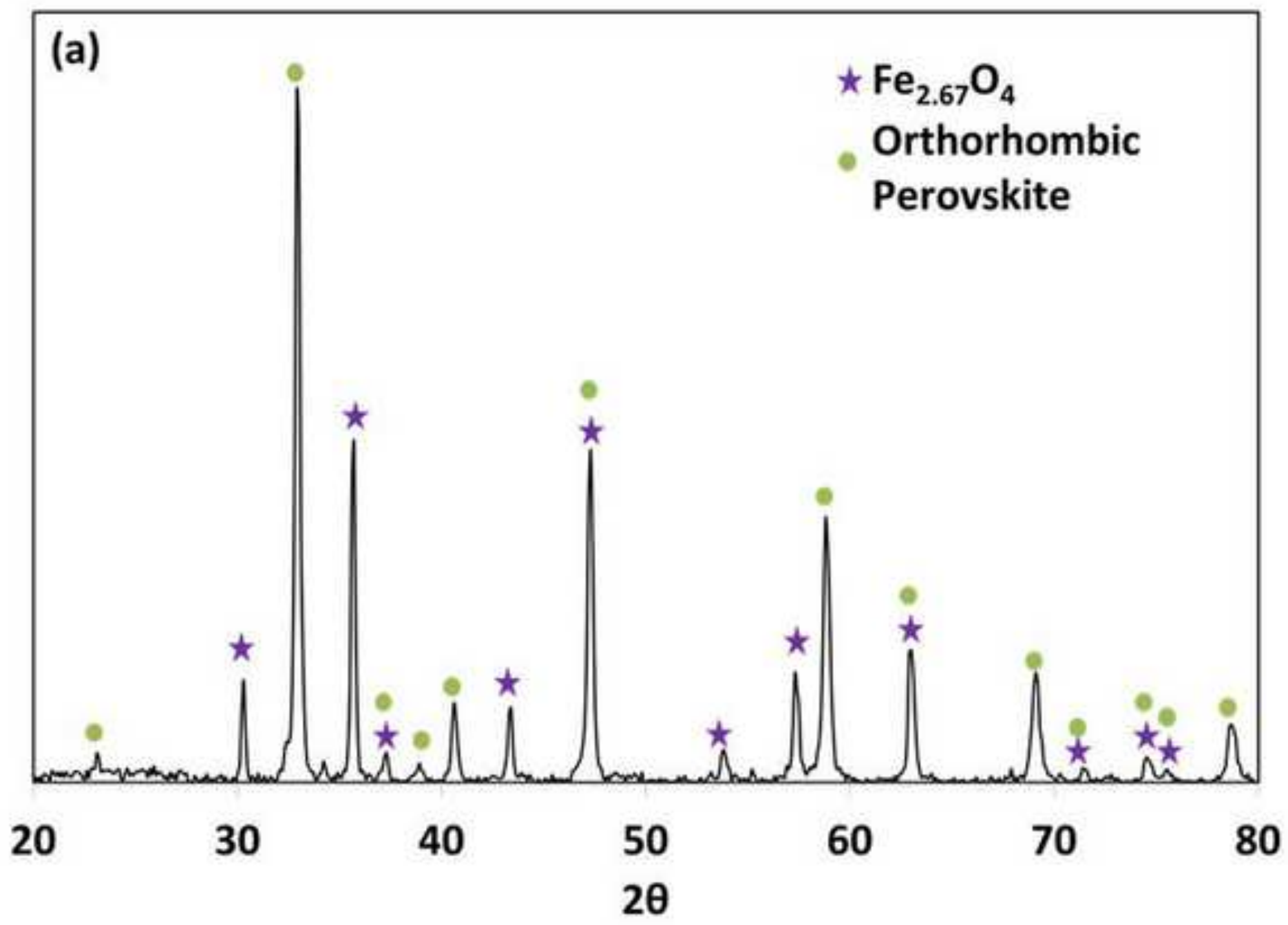




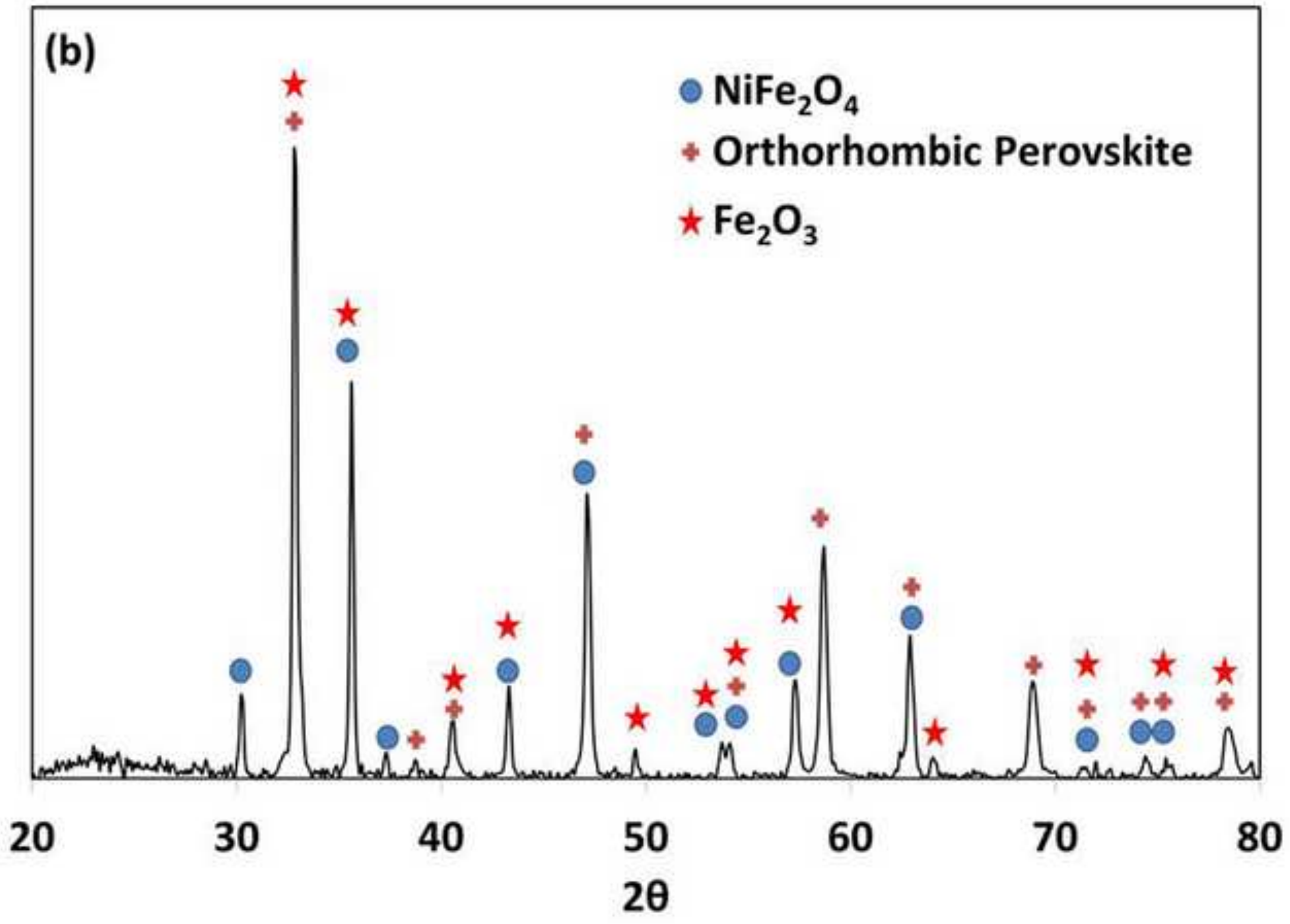




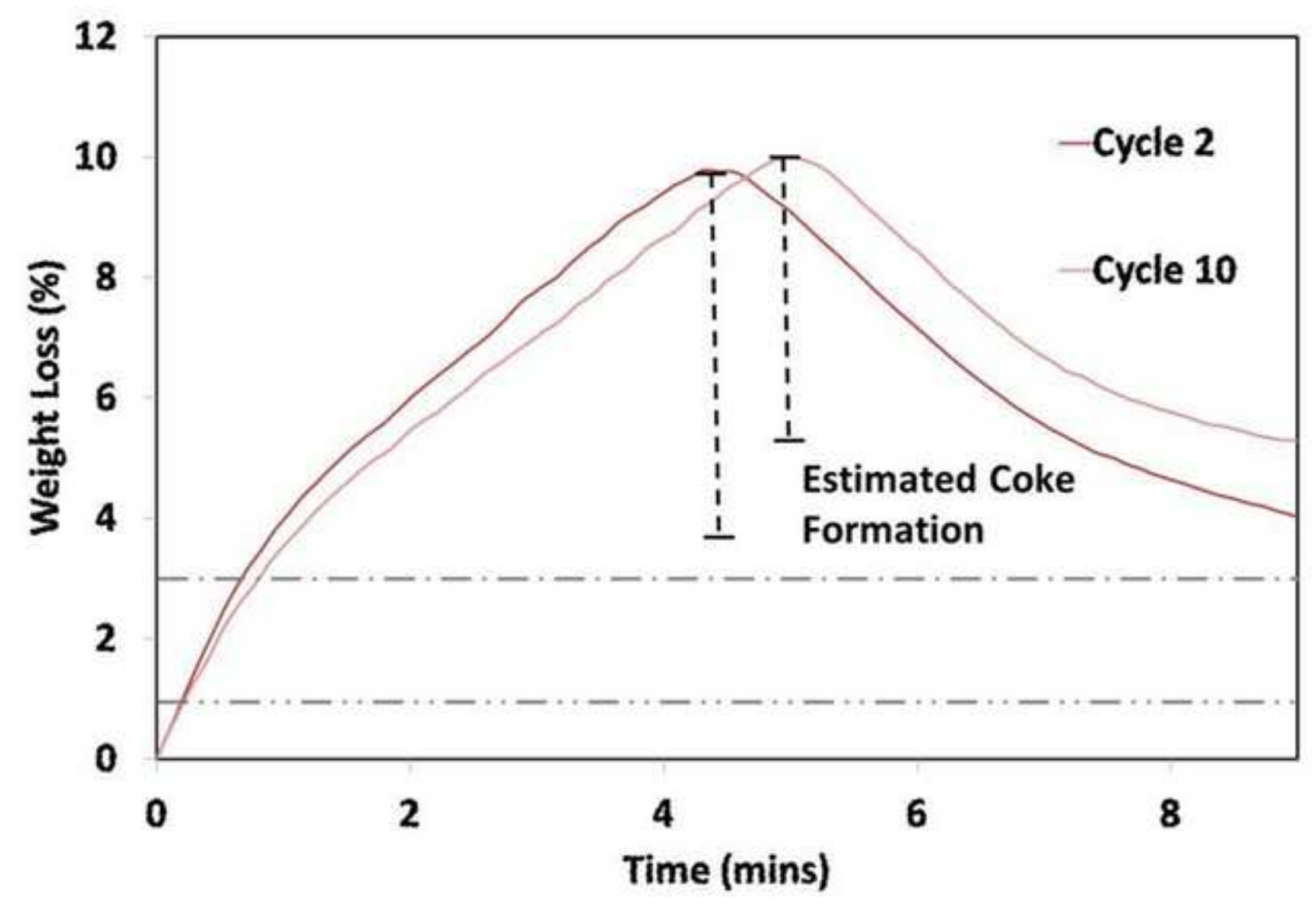




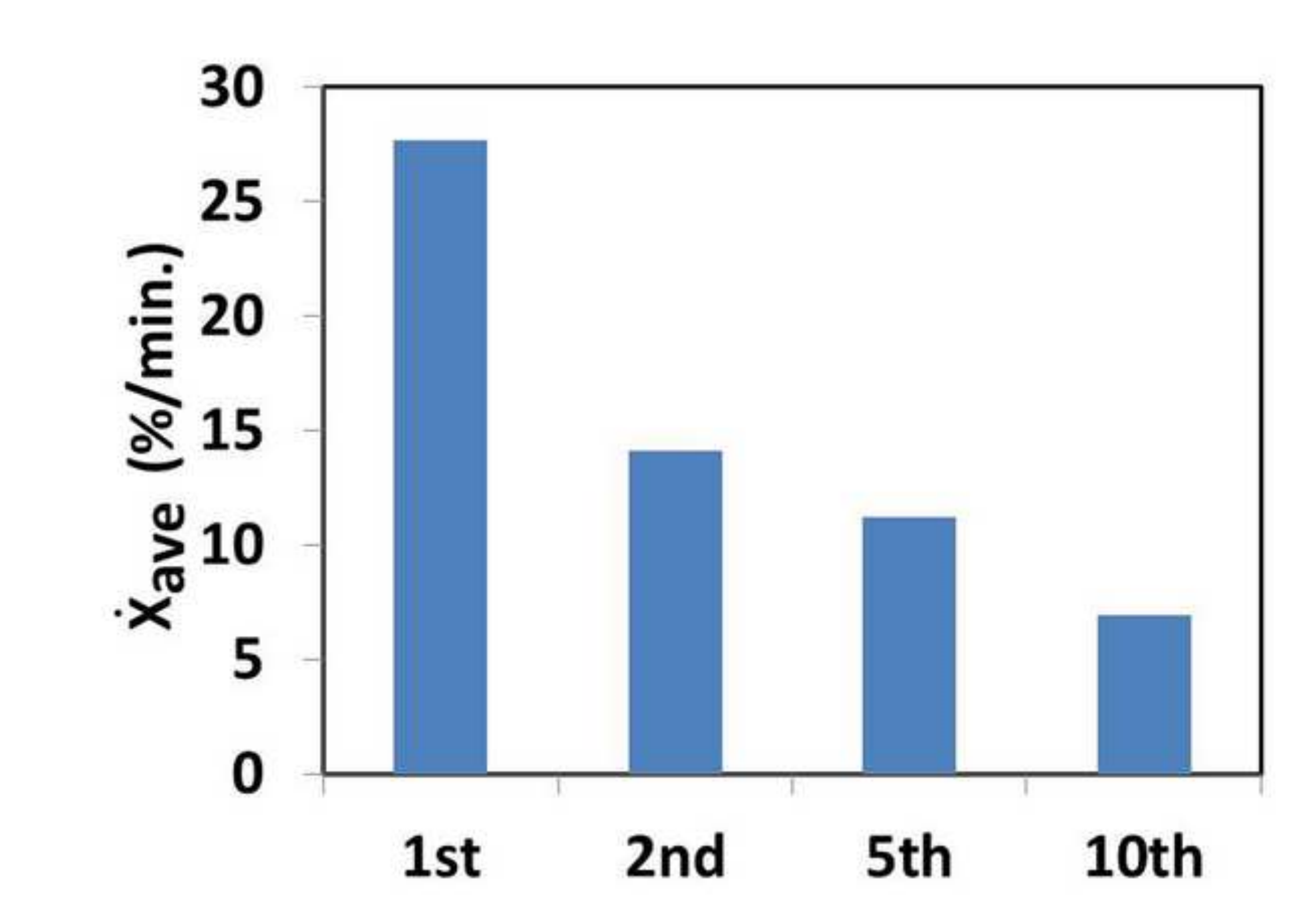

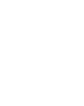

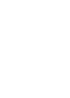

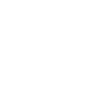




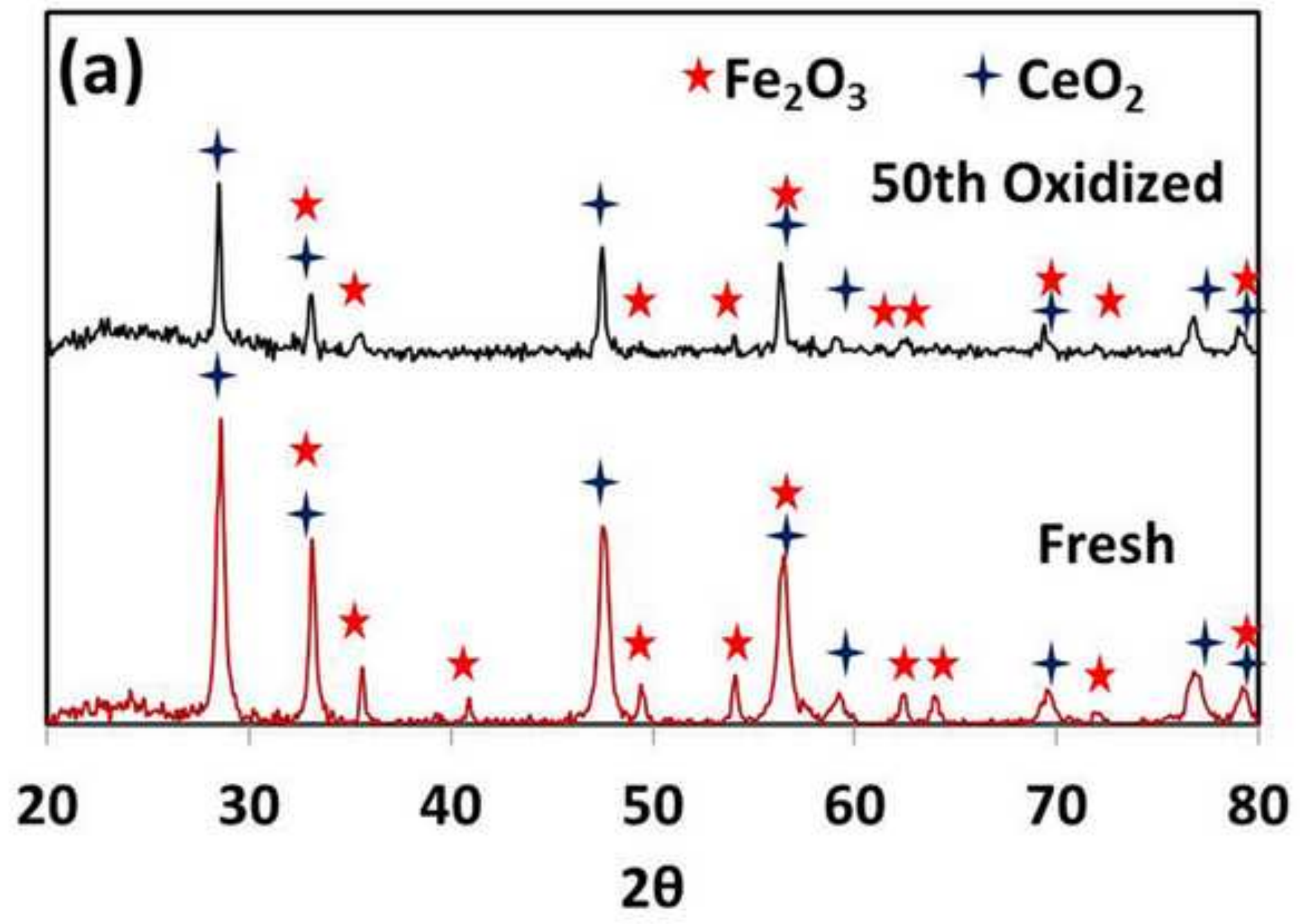




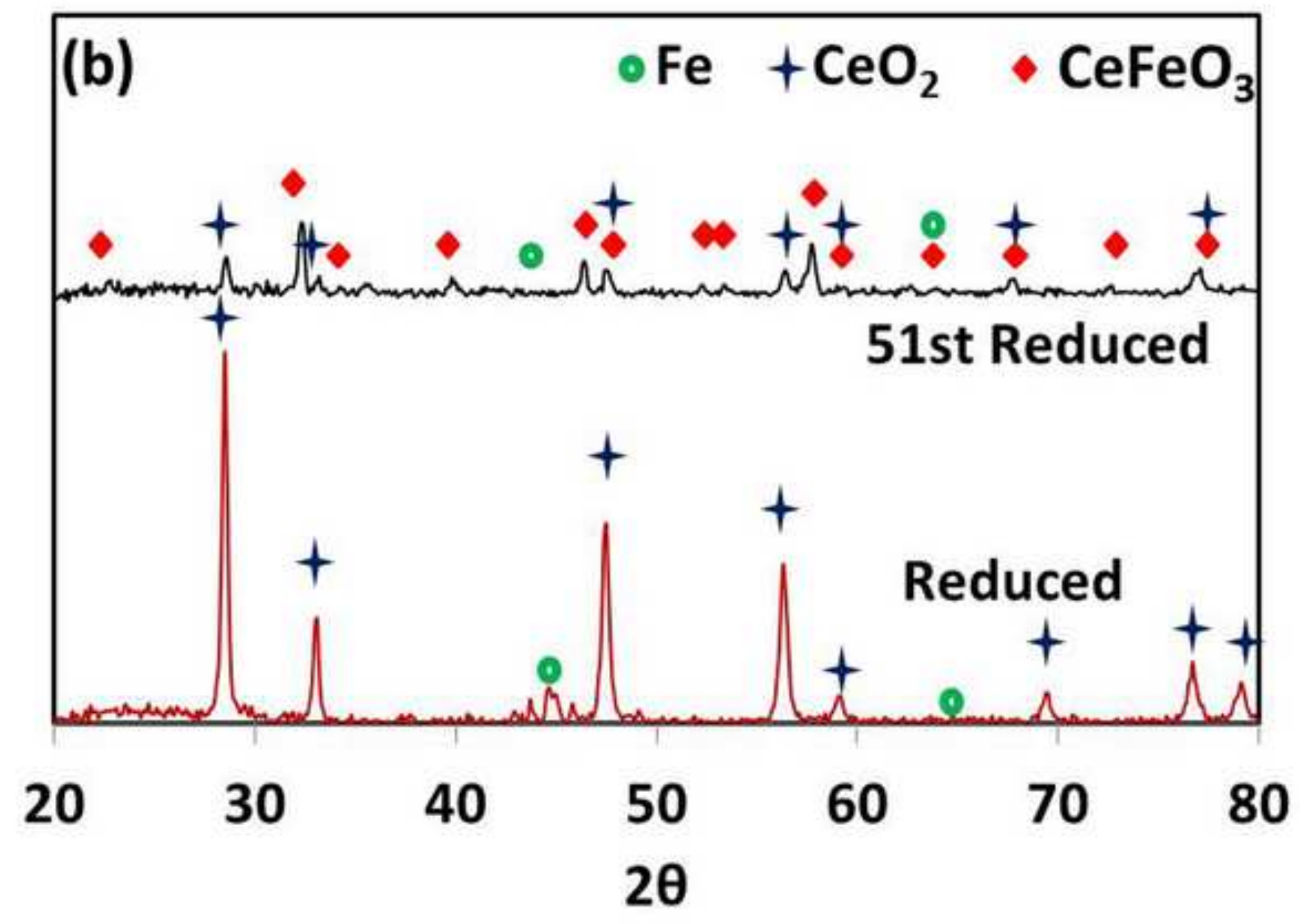




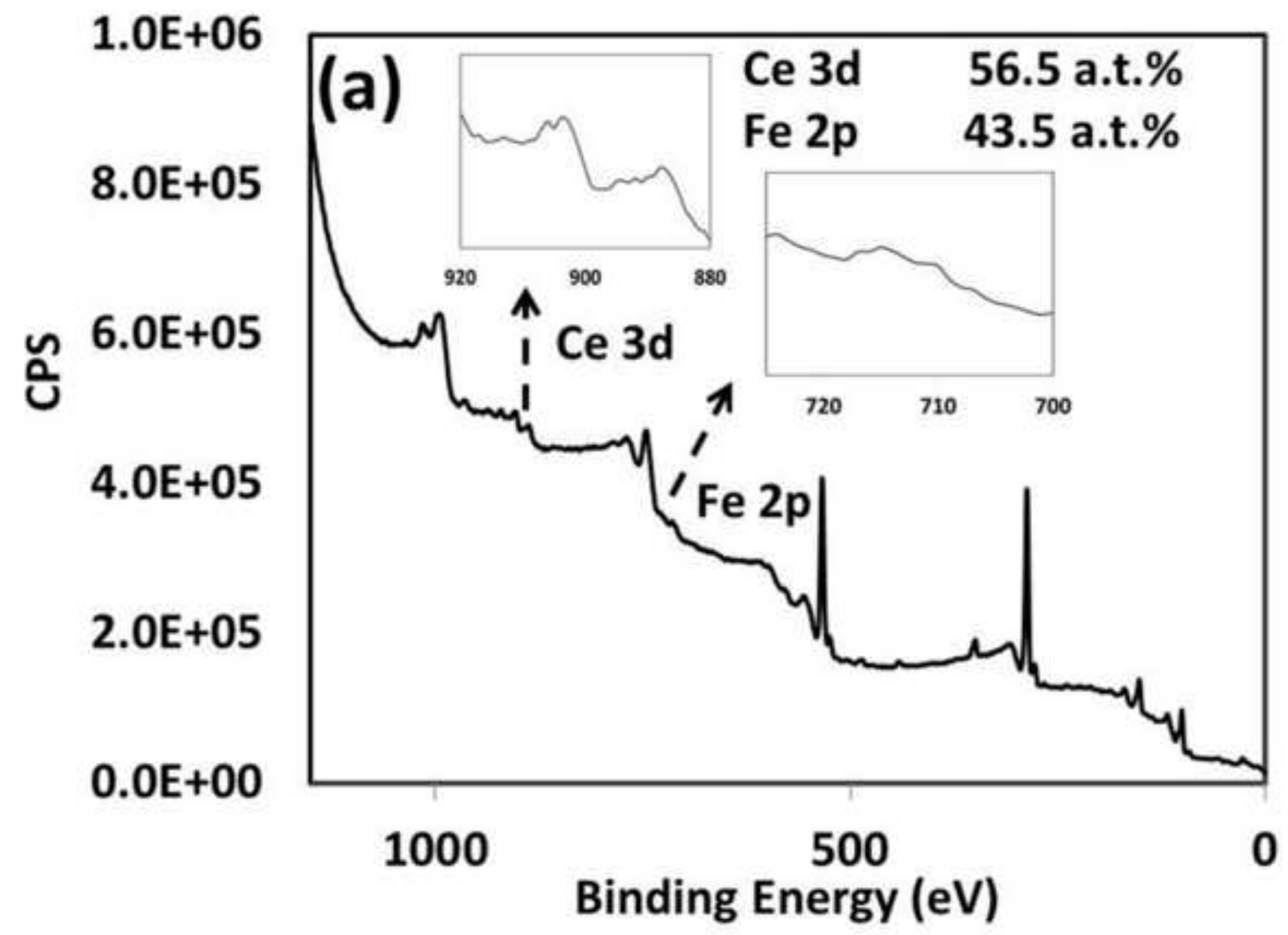




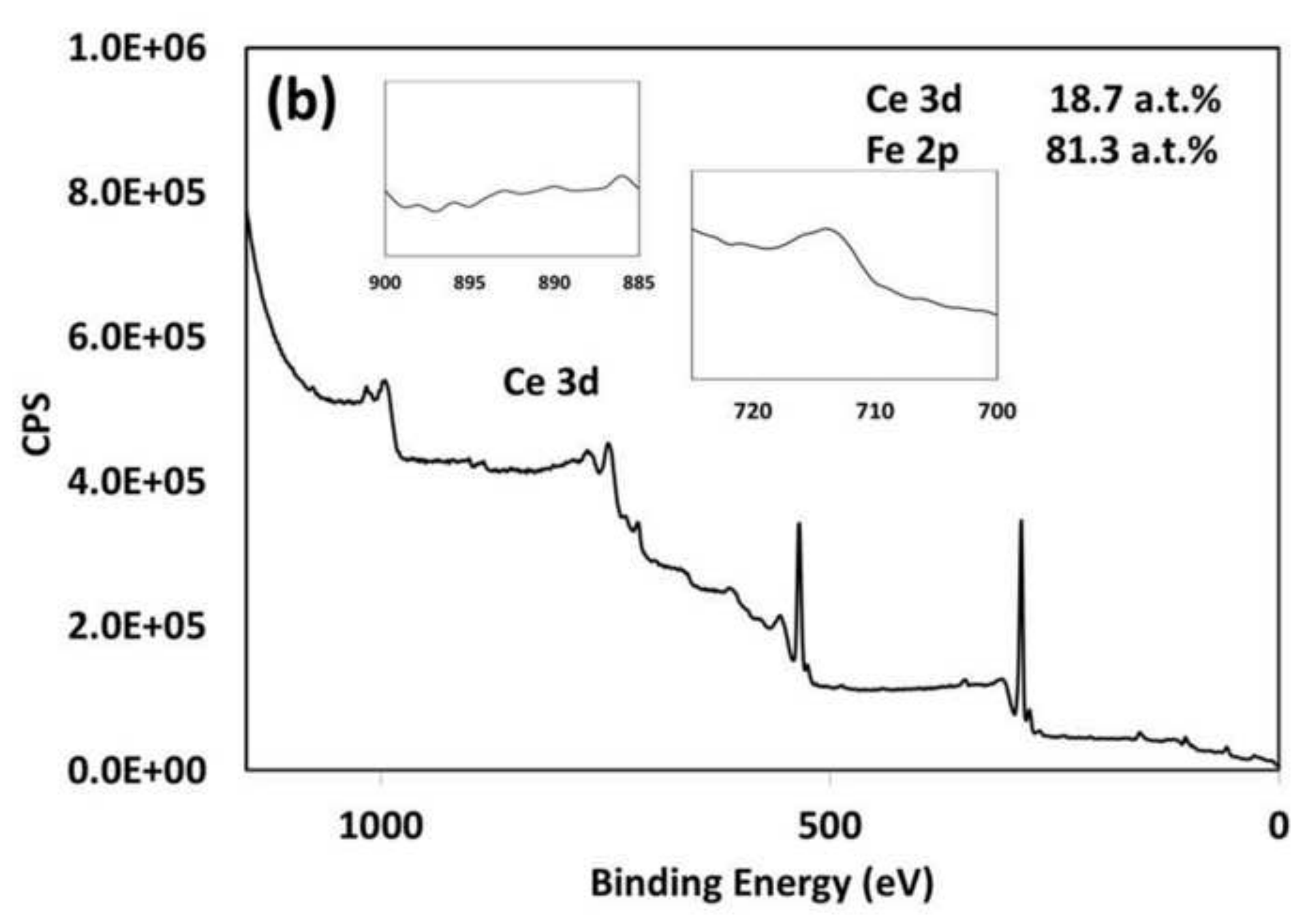




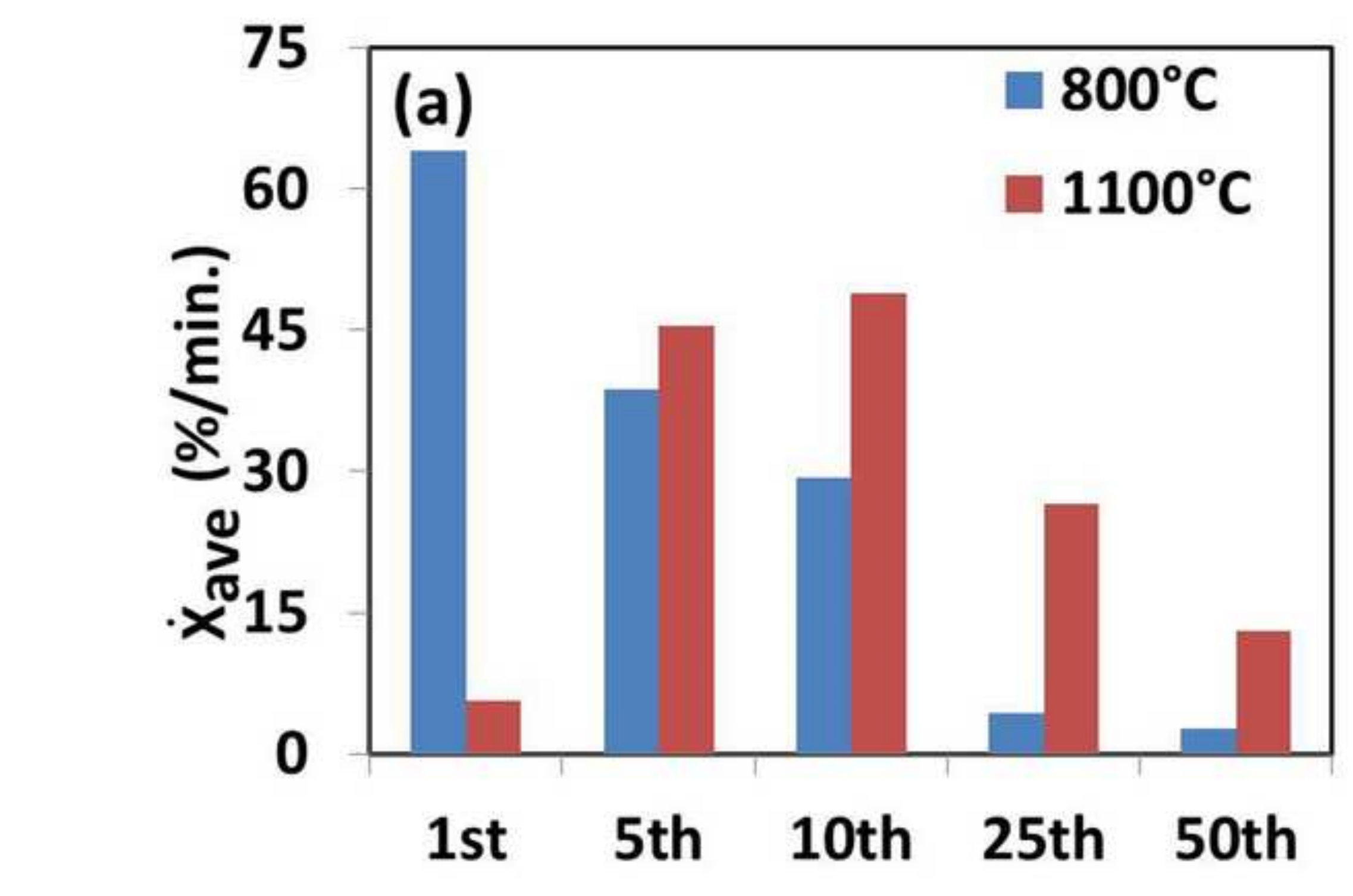




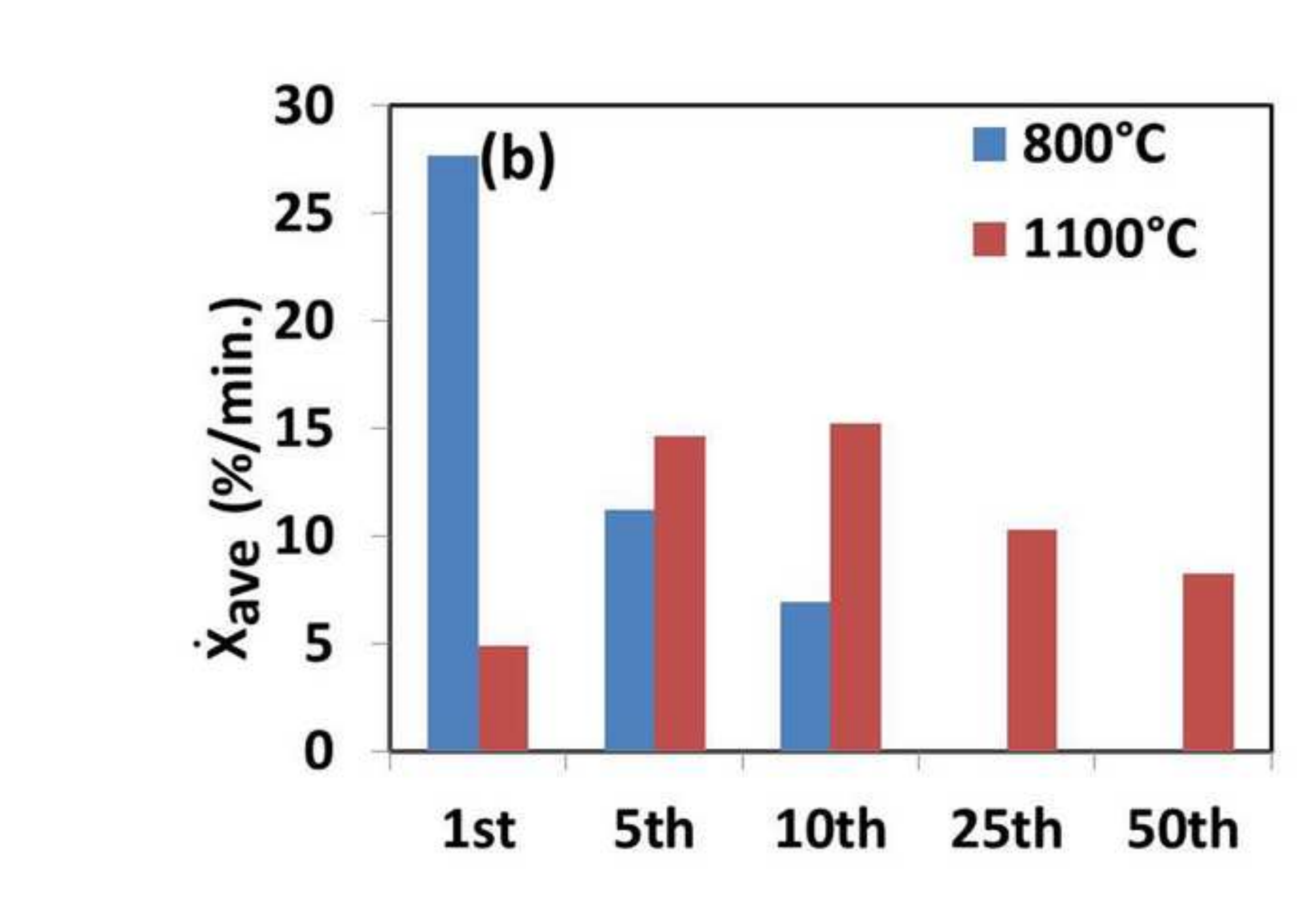

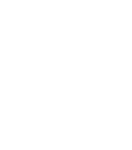
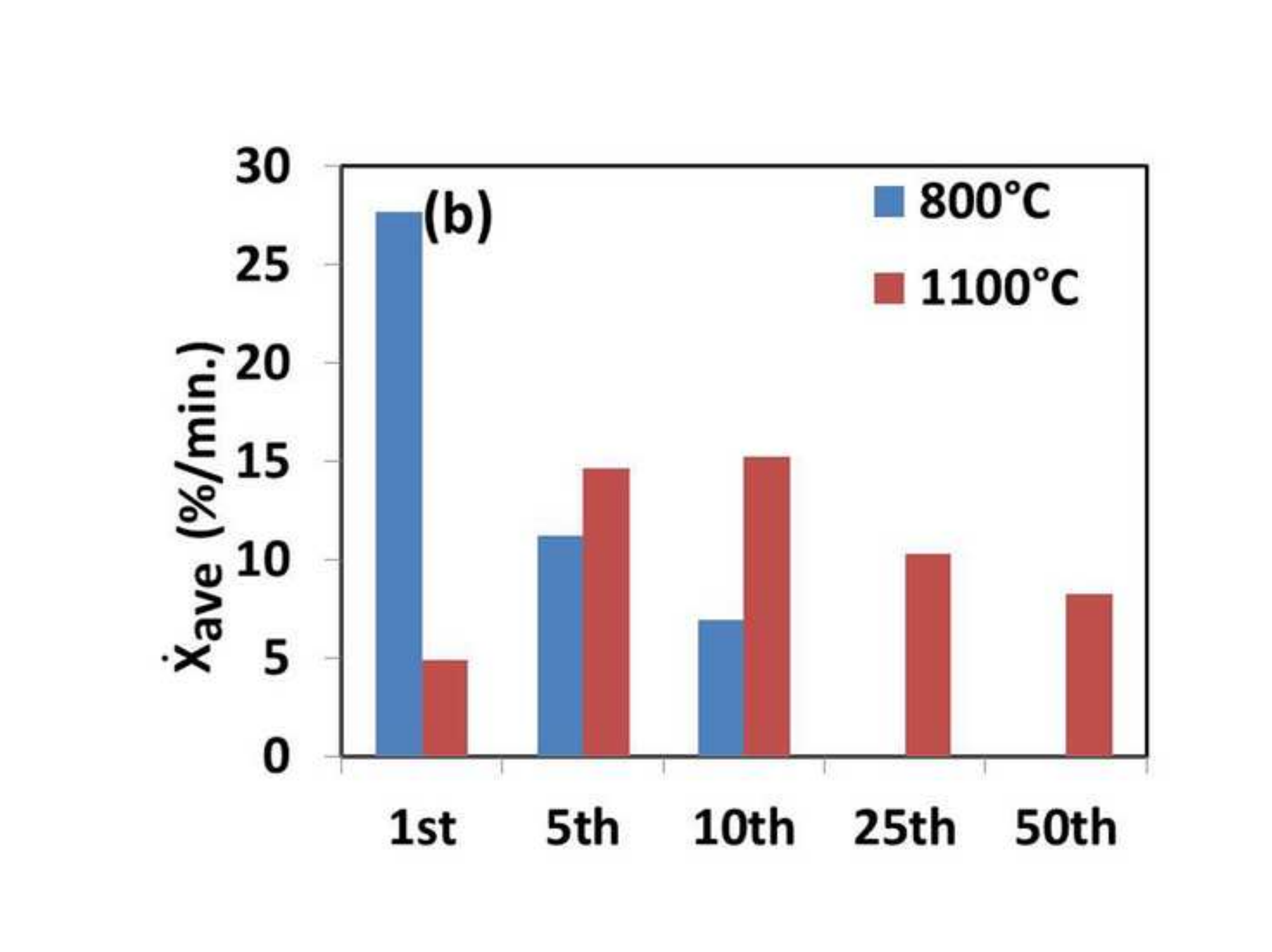

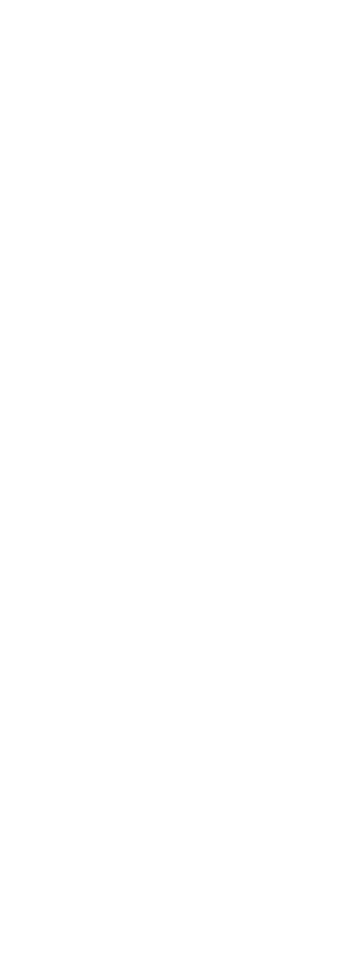

?

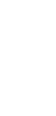
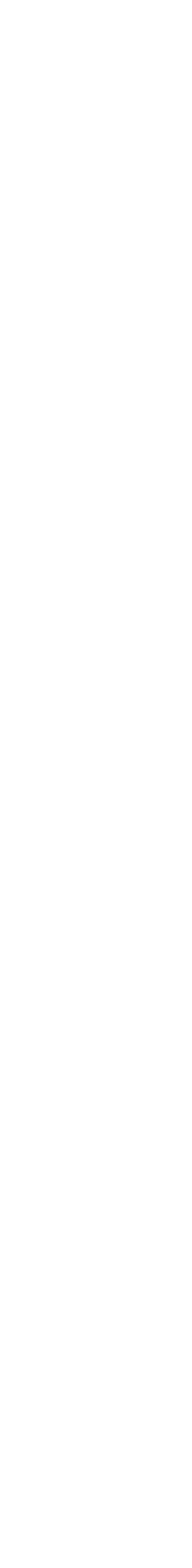

.
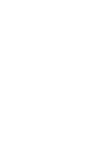

. 


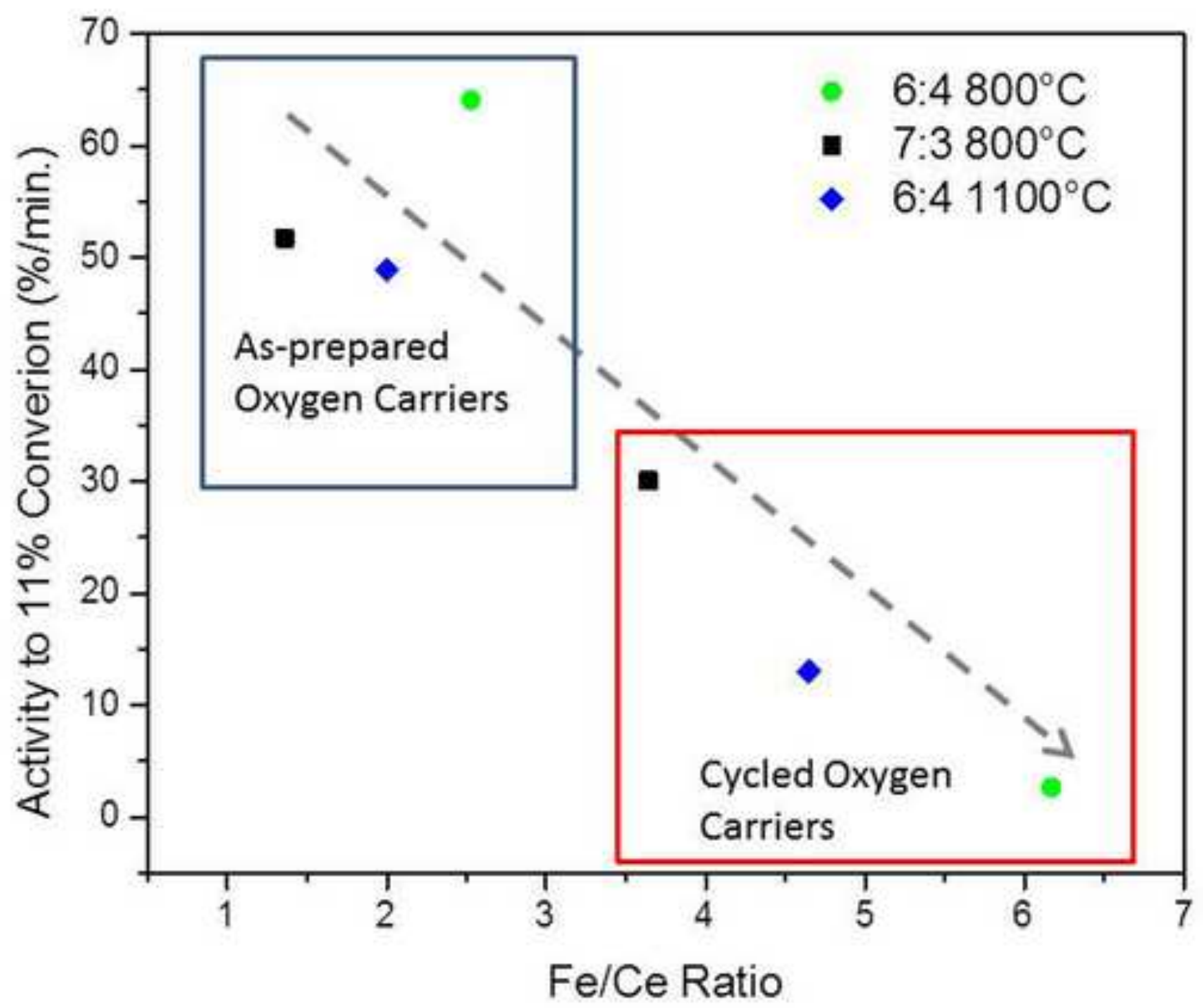




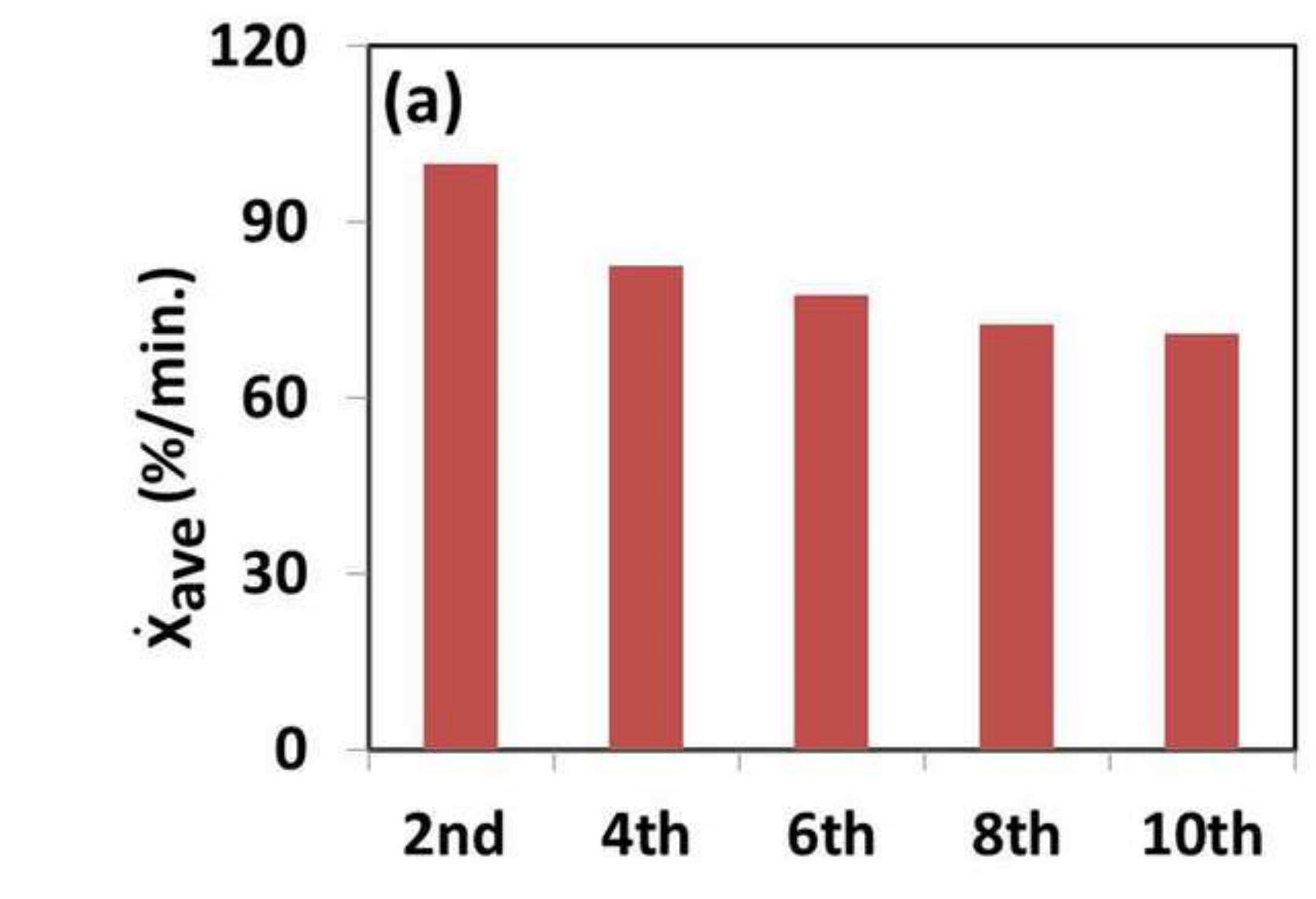




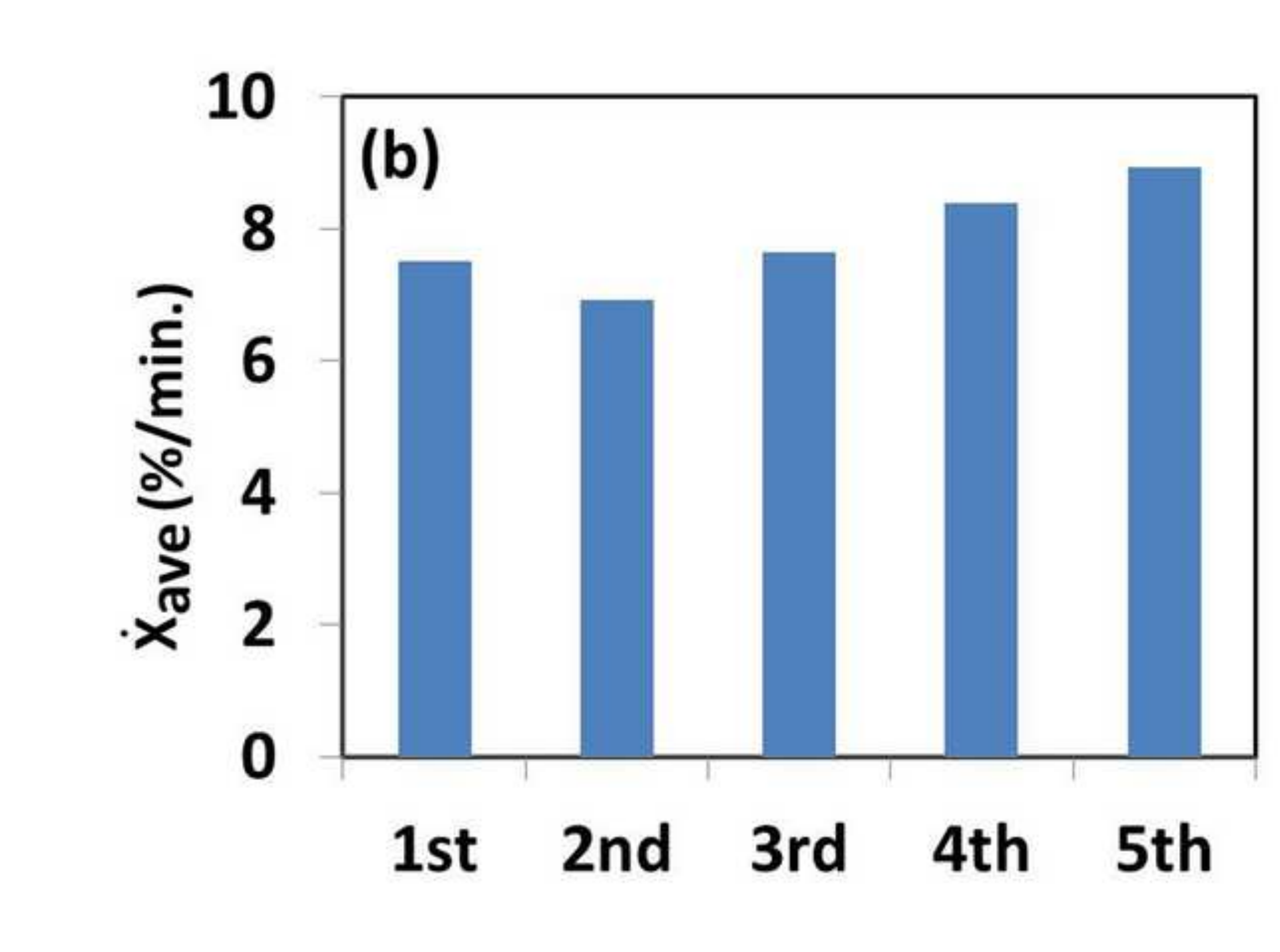

.

.
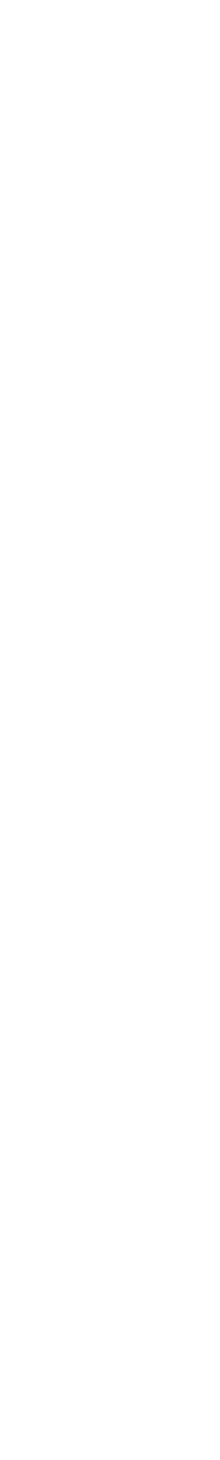

.
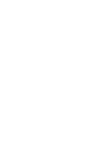

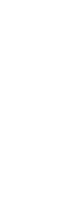

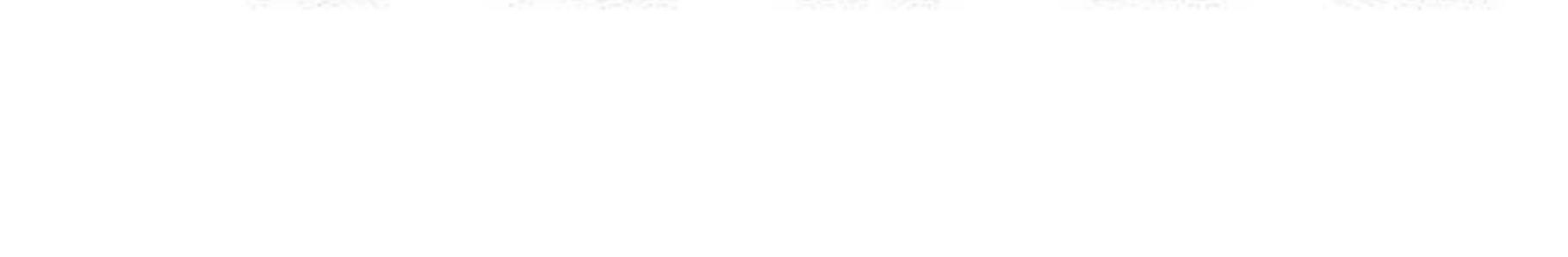




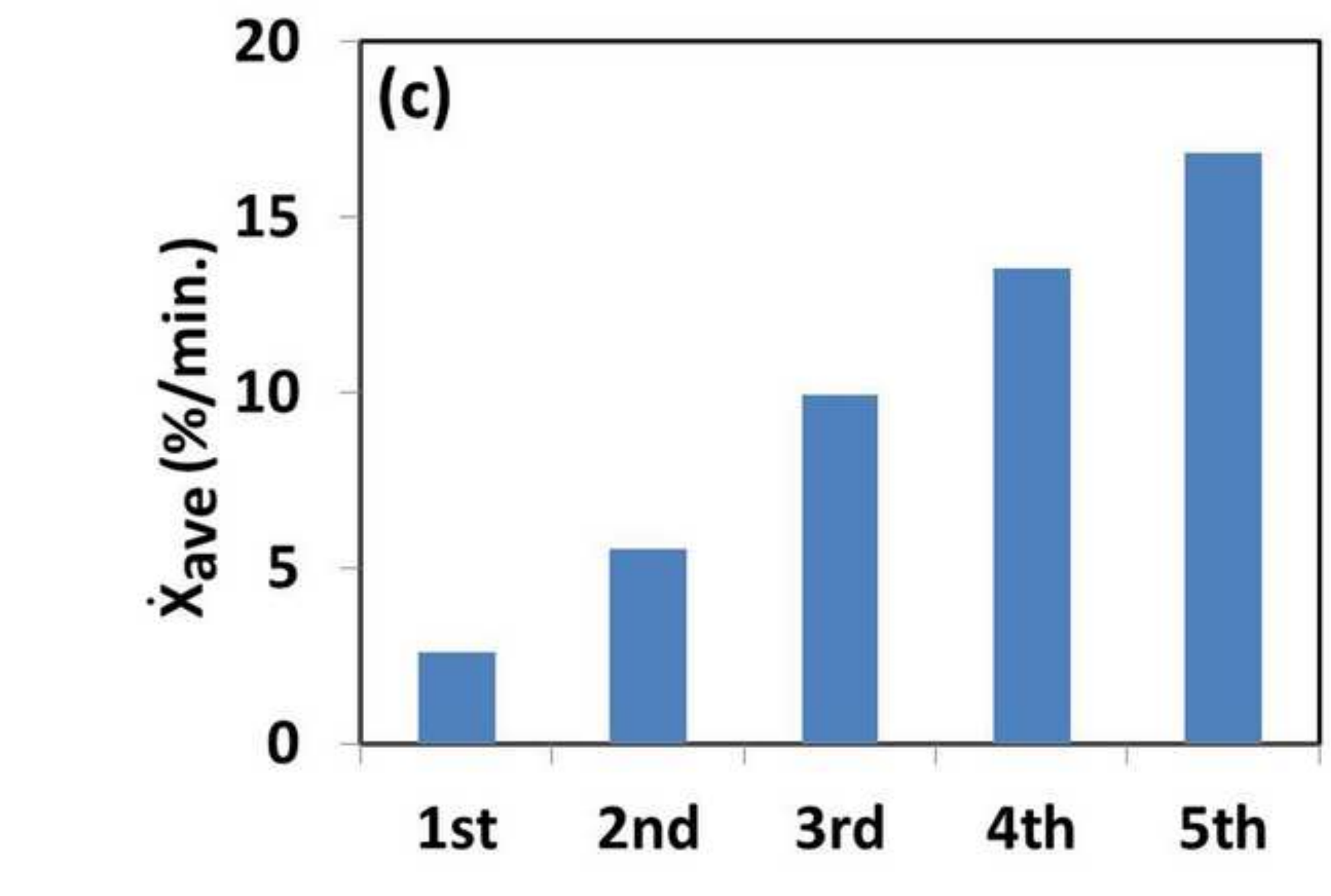




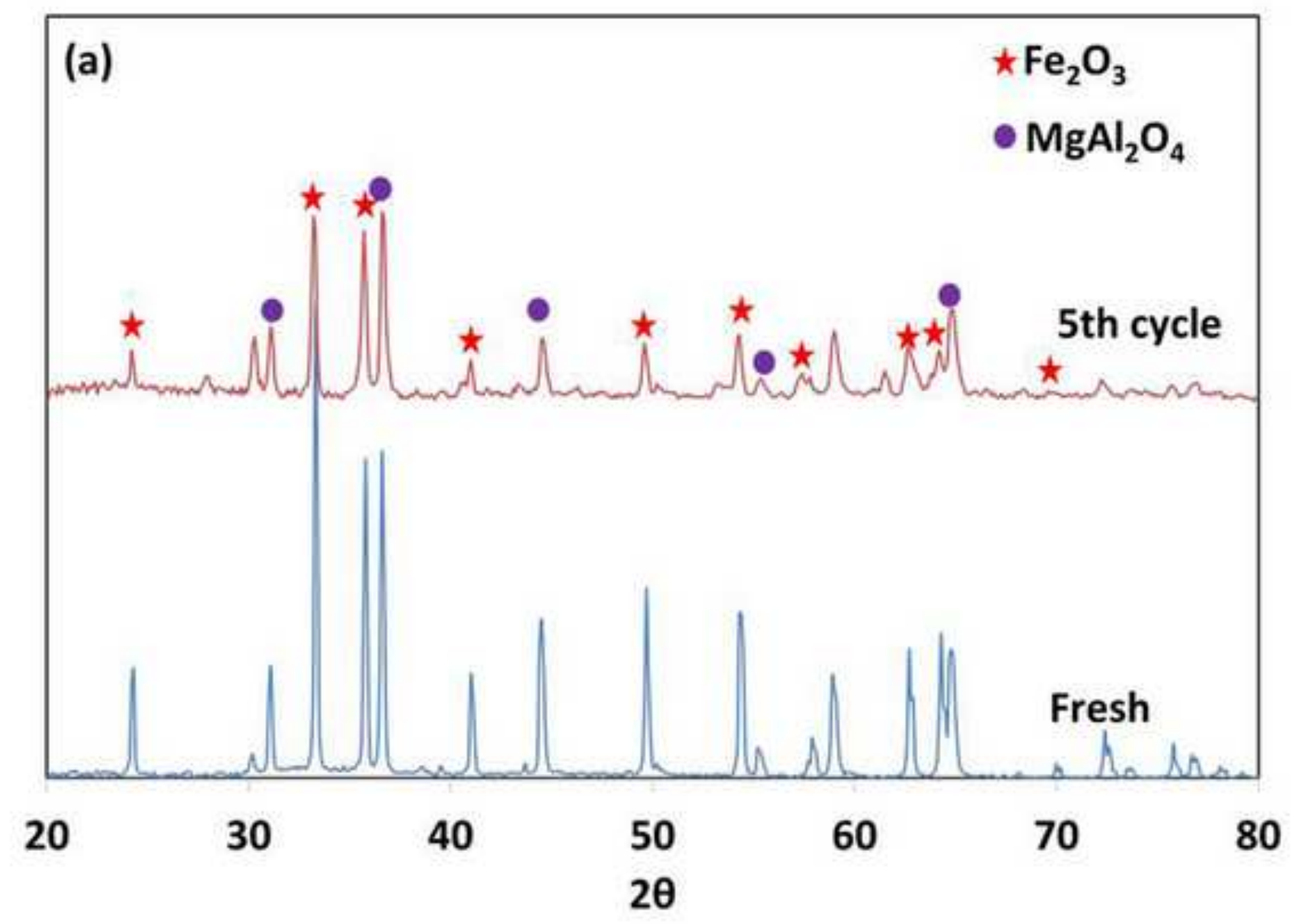

0




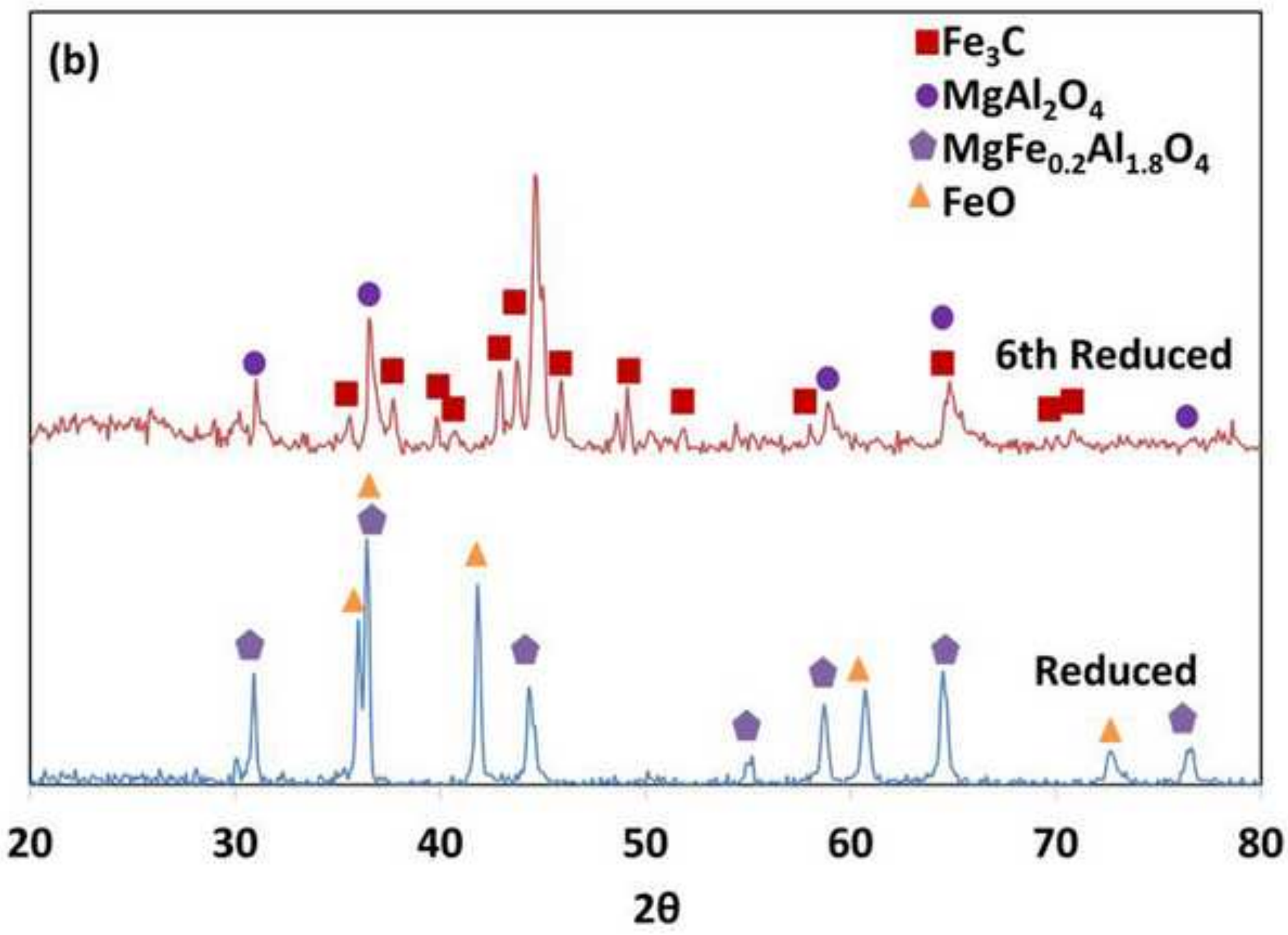




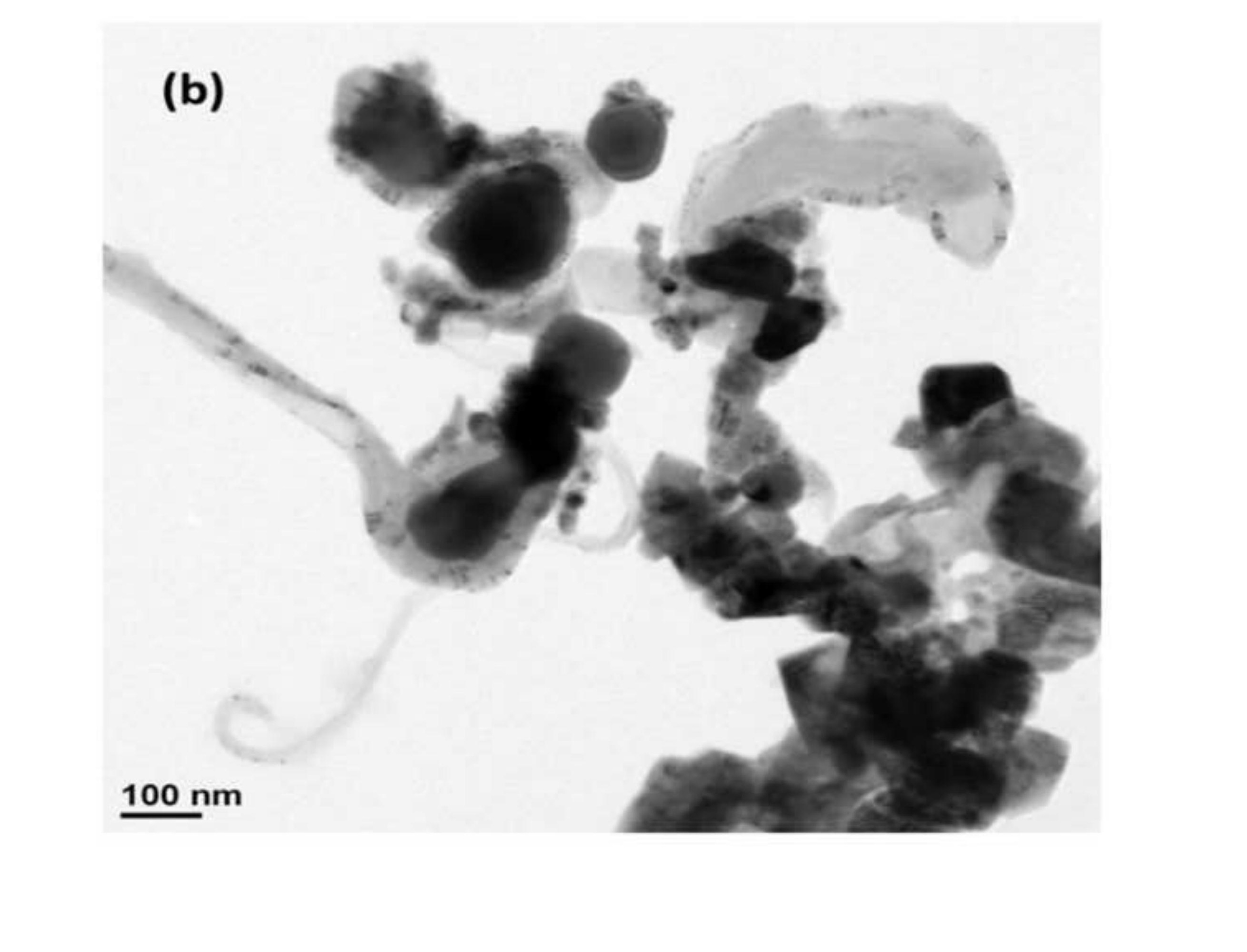

$100 \mathrm{~nm}$

(b)

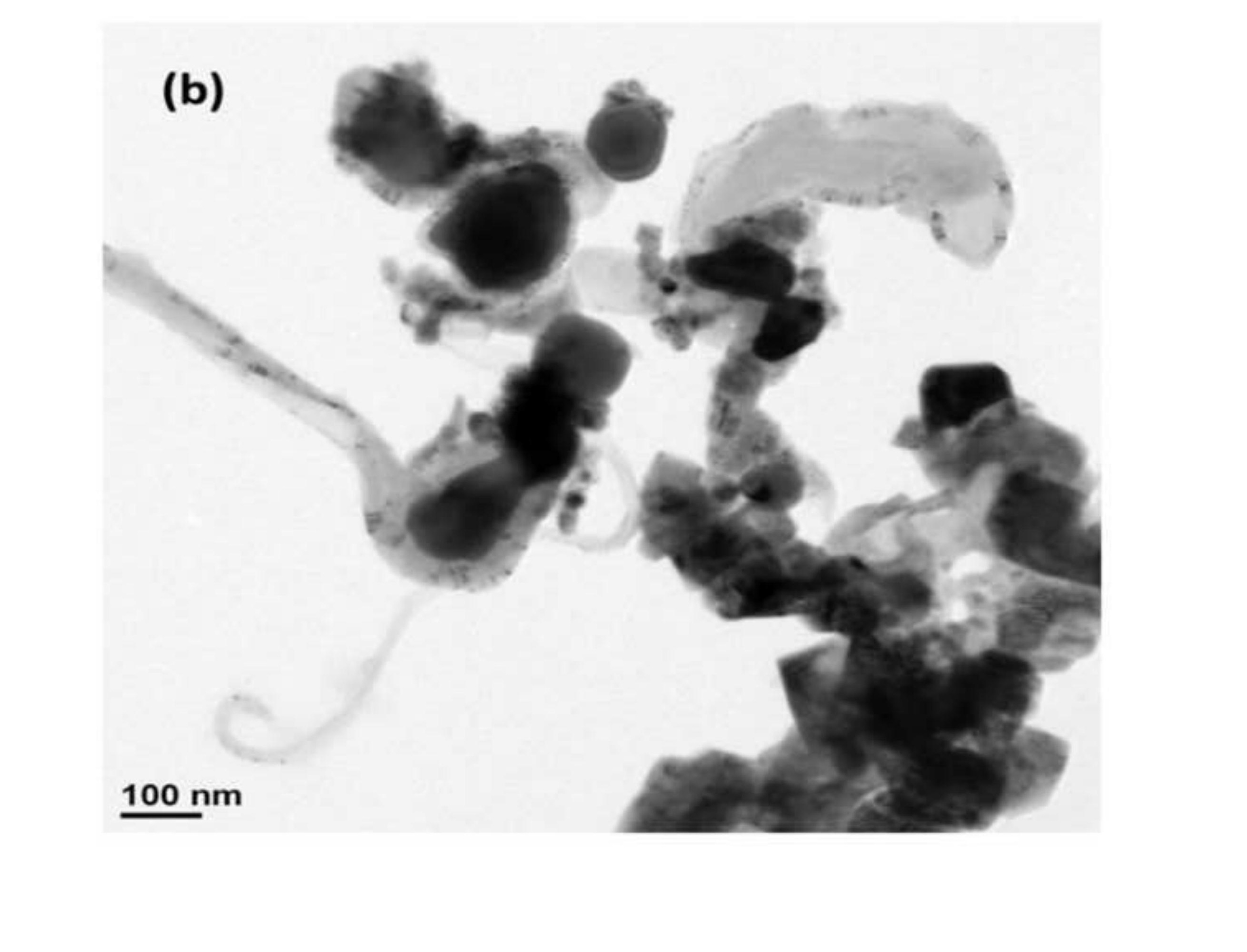

.

(

.


Figure 1- Comparison of the $2^{\text {nd }}$ cycle reduction of the various oxygen carriers by comparison of average conversion rate to achieve $11 \%$ and $33 \%$ conversion in (a) $10 \% \mathrm{H}_{2}$ and (b) $10 \% \mathrm{CH}_{4}$ at $900^{\circ} \mathrm{C}$.

Figure $2-$ Average conversion rate $\left(\% / \mathrm{min}\right.$.) to $33 \%$ conversion comparison between $2^{\text {nd }}$ and $10^{\text {th }}$ cycles of the various oxygen carriers at $900^{\circ} \mathrm{C}$ in $10 \% \mathrm{CH}_{4}$.

Figure 3- Average conversion rate to achieve $33 \%$ conversion of $\mathrm{Ca}_{0.8} \mathrm{Sr}_{0.2} \mathrm{Ti}_{0.8} \mathrm{Ni}_{0.2} \mathrm{O}_{3}$ supported $\mathrm{Fe}_{2} \mathrm{O}_{3}$ via CA method with (a) 10 cycles with $\mathrm{H}_{2}$ and (b) 50-cycles with $\mathrm{CH}_{4}$ at $900^{\circ} \mathrm{C}$.

Figure 4- XRD analysis of the (a) fresh and (b) 10-cycled CSTN supported iron oxide samples.

Figure 5- TGA curve of oxygen carrier weight loss TGA curve of cycle 2 and cycle 10 of the $\mathrm{Fe}_{2} \mathrm{O}_{3}$ : $\mathrm{CSTN}(\mathrm{CA})$ in $\mathrm{CH}_{4}$ at $900^{\circ} \mathrm{C}$. Vertical lines represent the estimated coke formation for the reaction with methane.

Figure 6- Average reduction rate to achieve 33\% conversion of $\mathrm{CeO}_{2}$ supported $\mathrm{Fe}_{2} \mathrm{O}_{3}$ (6:4) prepared via a co-precipitation route over the first 10 redox cycles during a 50 cycle experiment. Reducing gas: methane; Oxidizing gas: oxygen; Temperature: $900^{\circ} \mathrm{C}$.

Figure 7- XRD of the (a) fresh and after 50 cycles (b) $1^{\text {st }}$ reduced and $51^{\text {st }}$ reduced in methane and oxygen of the (6:4) co-precipitation $\mathrm{CeO} 2: \mathrm{Fe} 2 \mathrm{O} 3$ sample.

Figure 8- XPS of the (a) fresh and (b) $51^{\text {st }}$ oxidized ceria supported oxygen carrier

Figure 9- Average conversion rate to (a) $11 \%$ and (b) $33 \%$ conversion comparison of the $800^{\circ} \mathrm{C}$ $1,100^{\circ} \mathrm{C}$ sintered $\mathrm{CeO}_{2}$ supported $\mathrm{Fe}_{2} \mathrm{O}_{3}(6: 4)$ in $\mathrm{CH}_{4}$ at $900^{\circ} \mathrm{C}$ synthesized by a co-precipitation method. The lower sintered oxygen carrier does not achieve $33 \%$ conversion in the $25^{\text {th }}$ and $50^{\text {th }}$ cycles.

Figure 10- Comparison of the activity of $\mathrm{CeO}_{2}$ supported iron oxides versus the $\mathrm{Fe} / \mathrm{Ce}$ ratio on the surface. Cycle 5 and 50 data are used for the $1,100{ }^{\circ} \mathrm{C}$ sample. Cycle 1 and 50 data are used for the other samples.

Figure 11- Average conversion rate (\%/min) to $33 \%$ conversion of the $\mathrm{MgAl}_{2} \mathrm{O}_{4}$ supported $\mathrm{Fe}_{2} \mathrm{O}_{3}$ (7:3) via SSR tested in (a) 10 cycles with $\mathrm{H}_{2}$ and (b) 5-cycles with $\mathrm{CH}_{4}$ and (c) 5 cycles in $\mathrm{CH}_{4}$ of $1200^{\circ} \mathrm{C}$ sintered 4:6 $\mathrm{Fe}_{2} \mathrm{O}_{3}: \mathrm{MgAl}_{2} \mathrm{O}_{4}$ at a reaction temperature of $900^{\circ} \mathrm{C}$.

Figure 12- XRD of the (a) fresh and 5th oxidized samples of Fe2O3 MgAl2O4 SSR sample and (b) of the $1^{\text {st }}$ and $6^{\text {th }}$ reduced oxygen carrier.

Figure 13- TEM images of the $6^{\text {th }}$ reduced $\mathrm{MgAl}_{2} \mathrm{O}_{4}$ supported iron oxide. 


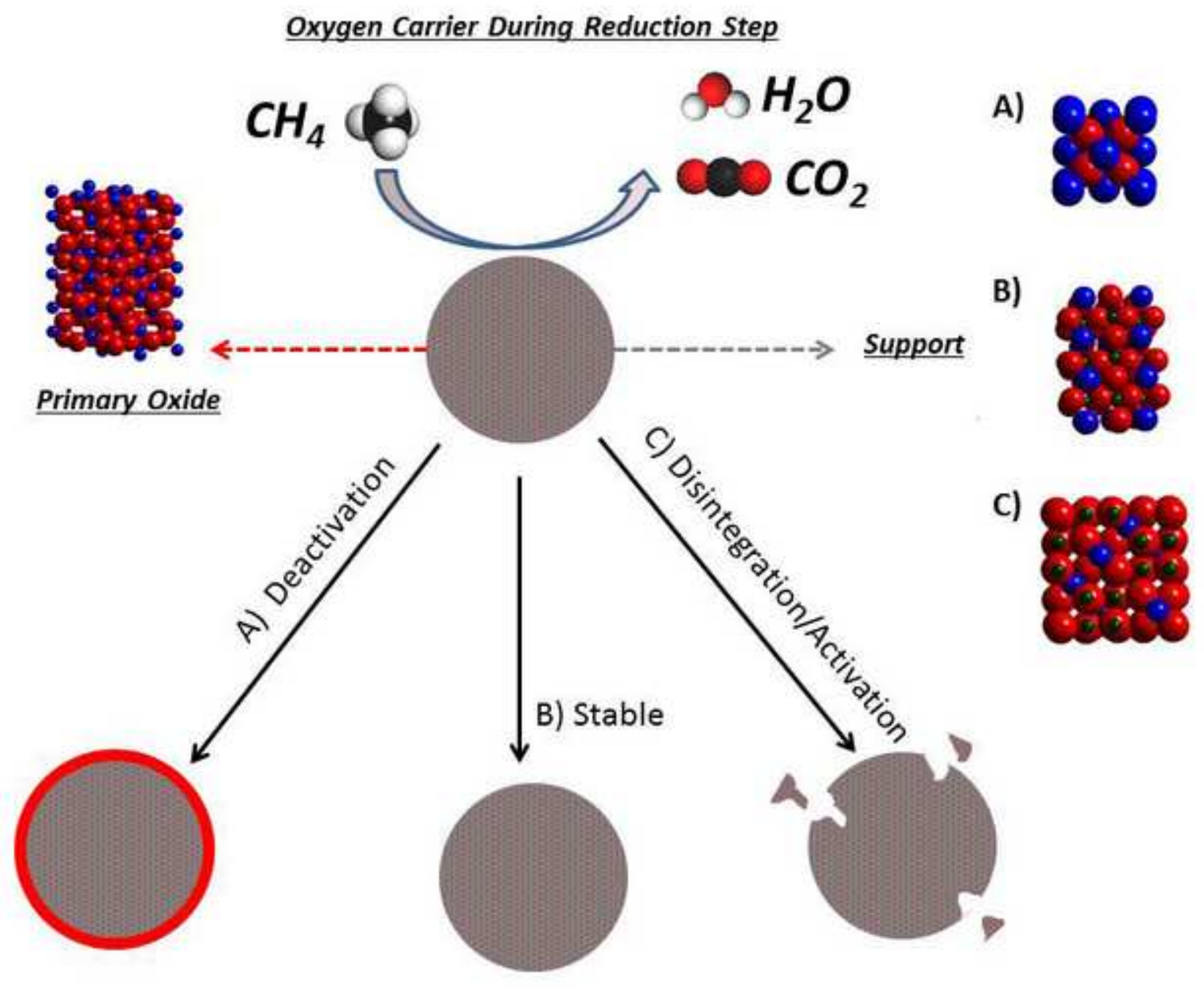

